University of Nebraska - Lincoln

DigitalCommons@University of Nebraska - Lincoln

Congreso internacional sobre iconografía

precolombina, Barcelona 2019. Actas.

$8-20-2020$

\title{
Los Templos Montaña y su simbología
}

Sarai Ramos Muñoz

Follow this and additional works at: https://digitalcommons.unl.edu/actas2019

Part of the American Material Culture Commons, Indigenous Studies Commons, Museum Studies Commons, Other History of Art, Architecture, and Archaeology Commons, and the Other Languages, Societies, and Cultures Commons

This Article is brought to you for free and open access by the Zea E-Books at DigitalCommons@University of Nebraska - Lincoln. It has been accepted for inclusion in Congreso internacional sobre iconografía precolombina, Barcelona 2019. Actas. by an authorized administrator of DigitalCommons@University of Nebraska - Lincoln. 


\title{
Los Templos Montaña y su simbología
}

\author{
Sarai Ramos Muñoz
}

Grup d'Estudis Precolombins (GEP), Departament d'Art i Musicologia, Universitat Autònoma de Barcelona. sarai.ramos@e-campus.uab.cat

\begin{abstract}
Resumen
El presente estudio es el inicio de una serie de artículos en los que se comparan e interpretan algunos de los templos montaña de la zona amerindia. Con el objetivo principal de comprender las relaciones existentes entre ellos así como las similitudes y diferencias entre la cosmovisión mesoamericana y la andina. Así pues, el estudio se plantea a partir de la analogía entre la arquitectura, la escultura y la pintura de dichos templos para poder vislumbrar, no solo el cómo, sino el por qué y para qué se realizaban dichos monumentos. Para ello, se plantea una aproximación interdisciplinar que permite analizar y comprender dichas relaciones y así obtener una mayor interpretación de la arquitectura amerindia y de su cosmovisión, de la importancia y el fuerte simbolismo de estos monumentos y del legado e influencias que derivan de ellos. El artículo se centra inicialmente en el análisis y comparación de algunos de los templos más representativos de Chavín de Huántar, Tiahuanaco, Palenque y Tikal.
\end{abstract}

Palabras clave: templo montaña, simbolismo, cosmovisión, Chavín de Huántar, Tiahuanaco, Palenque y Tikal

\begin{abstract}
This study is the beginning of series articles in which some of the mountain temples from the Amerindian area will be compared and interpreted. The main propose is to find the relations between temples whereas the similarities and differences between the Mesoamerican and Andean worldviews. Therefore the analogy between the architecture, the sculpture and the painting will help us to comprehend not only the how, but the why and what for these monuments were made. This lecture aims to analyse and understand these relationships to a greater interpretation of Amerindian architecture and its worldview;
\end{abstract}

the importance and the strong symbolism of these monuments and the legacy and influences that comes from them. For a start will be studied and compared some of the most representative temples of Chavín de Huántar, Tiahuanaco, Palenque and Tikal.

Keywords: mountain temples, symbolism, worldview, Chavín de Huántar, Tiahuanaco, Palenque y Tikal

\section{()ㅜㅇㅜ}

\section{Introducción}

A lo largo de la historia, las diferentes culturas amerindias realizaron enormes complejos ceremoniales (CoC) donde la arquitectura, la escultura y la pintura se cohesionaban entre sí, creando unos monumentos magníficos y solemnes. Dentro de estos complejos arquitectónicos (CA), el principal foco de atención está en los llamados Templo Montaña (TM).

A continuación, se analizan y compararan algunos de los monumentos más relevantes de dos centros ceremoniales (CeC) mesoamericanos, Tikal y Palenque; y dos CeC andinos, Chavín de Huántar y Tiahuanaco, centrándose en su arquitectura sagrada, su imagen y su función; así como en la cohesión entre la arquitectura, la escultura y la pintura. Asimismo, se estudia la integración de estos edificios en la naturaleza y la importancia de la cosmovisión amerindia para entender las formas arquitectónicas ${ }^{1}$.

1 Para agilizar la lectura, en el siguiente artículo se usan diferentes abreviaturas de términos concretos que se van repitiendo durante todo el discurso empleando las iniciales de cada palabra, apareciendo entre paréntesis la primera vez que son mencionadas en el texto.

Publicado en Congreso internacional sobre iconografía precolombina, Barcelona 2019. Actas, Victòria Solanilla Demestre, editora (Lincoln, Nebraska: Zea Books, 2020). https://doi.org/10.32873/unl.dc.zea.1249 


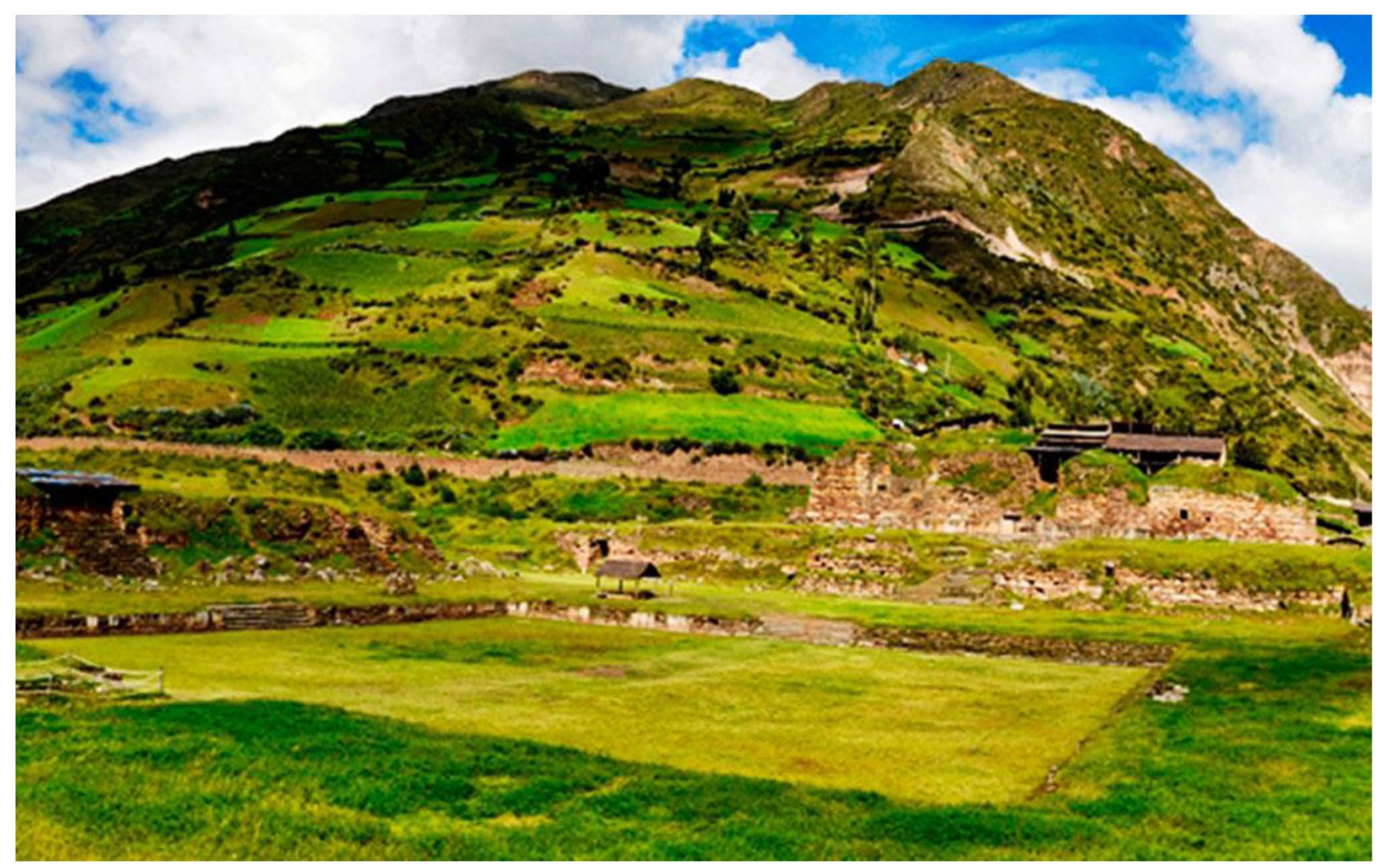

Lámina 1a. Vista aérea actual de Chavín de Huántar,.

\section{Cosmovisión y simbología en la arquitectura amerindia}

La ubicación de estos $\mathrm{CeC}$ amerindios es muy significativa, porque gracias a ella se crea una geografía sagrada donde la arquitectura se integra en la naturaleza. Estos CA suelen estar situados cerca de afluentes de agua y próximos a montañas y sierras; creando así una visión mítica del territorio elegido (Láminas 1a, 1b, 1c y 1d). Al mismo tiempo, la sacralidad del paisaje dota a los edificios de un fuerte carácter sagrado y simbólico convirtiendo los TM en la propia representación del axis mundi. Así pues, en estos $\mathrm{CeC}$ se consigue una interacción entre el paisaje creado, diseñado y pensado; con el natural y el salvaje (AAVV, 2002: 160-161; Barbier, 1997; Campagno, 2007; Carceller, 2010: 7-19; Gussinyer, 1992-93: 183-230; Longhena, 2005: 122-125; López Austin y López Lujan, 1996; López Austin, 1994: 9-17; Sondereguer, 1989; Sondereguer, 1998: 7-22; Sondereguer, 2006 y Vidal, 2002).

Dentro de estos CoC, los monumentos más importantes son los TM; una representación alegórica de la Montaña Sagrada (MS), es decir, son el centro del cosmos y del CeC en sí. Los TM son el lugar donde se fusionan los pensamientos cósmicos, las ideas mítico-religiosas y el poder de los dioses y los gobernantes divinizados. Así pues, los TM son la representación de la Montaña Primogénita (MP) y la plasmación de su concepción del Universo. Es Tierra por su forma cuadrada que marca los cuatro puntos cardinales y el punto central, visible en la escalinata y el Templo Superior (TS); convirtiendo el TM en el centro del mundo. Es Cielo, porque la Pirámide Escalonada (PE) es la escalera de ascensión al TS y el lugar más próximo a los dioses. Y es Inframundo, porque las diferentes escaleras, o la rampa de descenso a la tumba, forman una Pirámide Invertida (PI) que lleva a la parte interna y más oscura de la $\mathrm{PE}^{2}$ (Carceller, 2010; López Austin y López Lujan, 1996; López Austin, 1993; López Austin, 1994: 17-23; Sondereguer, 1989; Sondereguer, 1998; Sondereguer, 2006 y Vidal, 2002).

Por otro lado, tanto en los TM, como en los CeC, se aprecia la contraposición y la dualidad del mundo amerindio. Podemos verlas en el concepto de macro-microcosmos a través de las formas y los tamaños, donde la base cuadrada de la PE y la del TS dan paso de una planta más grande a otra más pequeña centralizada (a modo de lupa). De este modo se remarca la importancia del TS, además de 


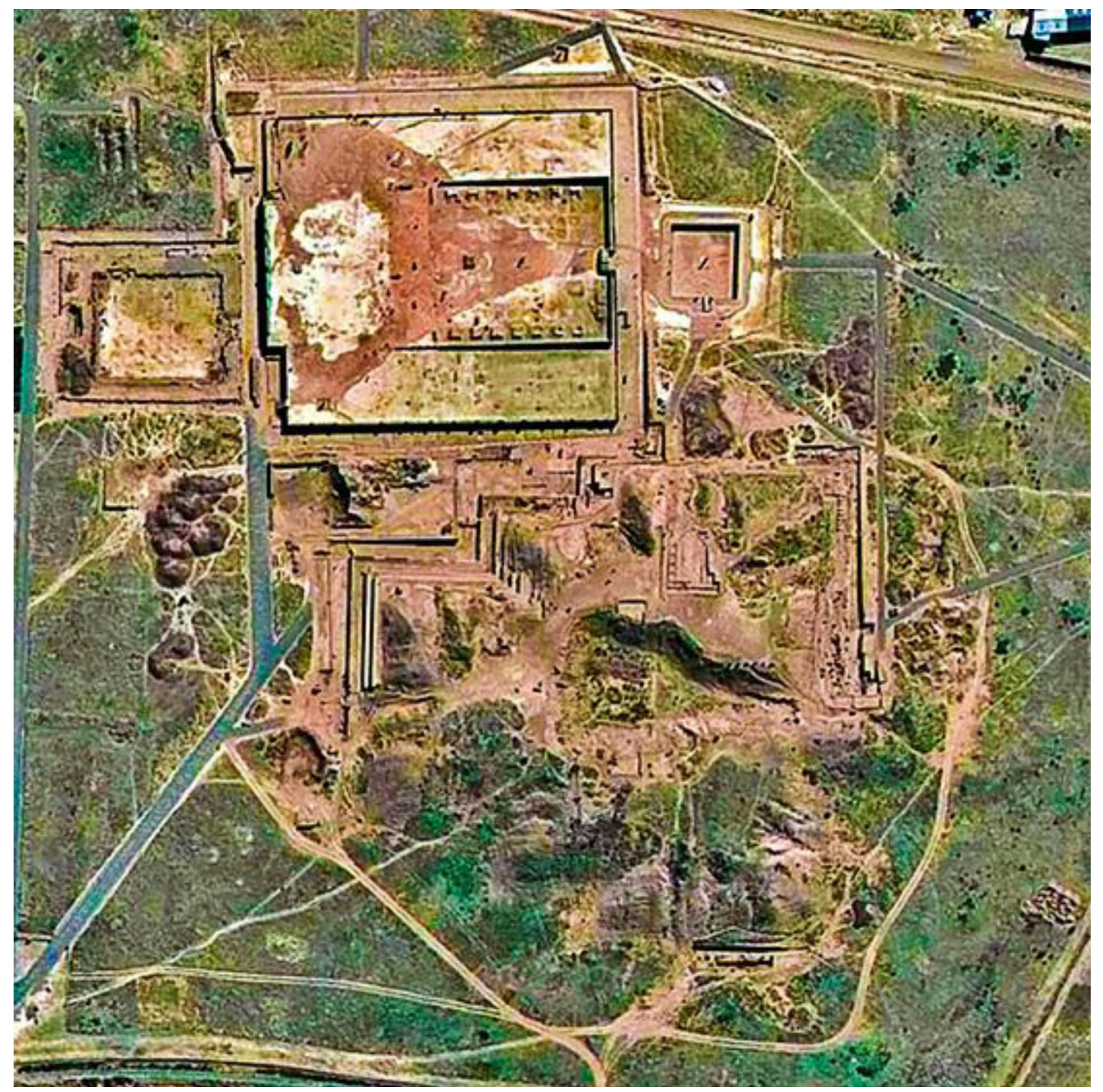

Lámina 1b. Vista aérea actual de Tiahuanaco.

la magnífica visión que se tenía de los rituales llevados a cabo en él, en las escaleras y en la plaza. En la contraposición de las plantas cuadradas del TM y el TS con la circular de la plaza se aprecian, tanto las dualidades y contraposiciones del macro-microcosmos, como la contraposición de lo masculino y lo femenino y la separación del ritual privado y el público. Además, a veces, se puede apreciar la gran sofisticación arquitectónica de las plantas amerindias, donde la idea del cuadrado evoluciona hasta la llamada "cruz andina", u otros modelos más complejos (ej. Pirámide de Akapana, Tiahuanaco). Tiene que ver con una voluntad retórica, tanto a nivel religioso como propagandístico, para ilustrarlo que representa cada monumento y el papel que desempeña dentro del propio CoC (AAVV,
2002; Alcina, 1991; López Austin, 1993; Sondereguer, 1998: 7-22 y Sondereguer, 2006).

El TM y las edificaciones más próximas, se convierten en el foco principal del CeC y son el lugar donde se llevan a cabo los rituales más importantes. El TM es el hábitat del Dios y, en algunos casos, la morada del gobernante divinizado a su muerte (ej. tumba Pacal, Palenque). Es el punto focal del CA y la plasmación del axis mundi entendiéndolo como la ceiba madre. Así pues, el TM es el centro de todo y el medio que utilizaban para comunicarse, tanto con los dioses y los seres sobrenaturales del Cielo y el Inframundo, como sus antepasados y ancestros (AAVV, 2002; Alcina, 1991; Carceller, 2010; López Austin, 1993 y López Austin, 1994).

2 Muchos de los TM amerindios tienen 13 o 9 plataformas y, por ello, se suele relacionar con los 13 niveles del Cielo o los 9 estratos del Inframundo. Es decir, el número de plataformas que tiene la PE y/o la escalinata está estrechamente relacionado con su cosmovisión y su concepción del Universo. Además, los TM siguen principios arquitectónicos comunes basados en la morfoproporcionalidad, la geometría sagrada, los números áureos, etc. 


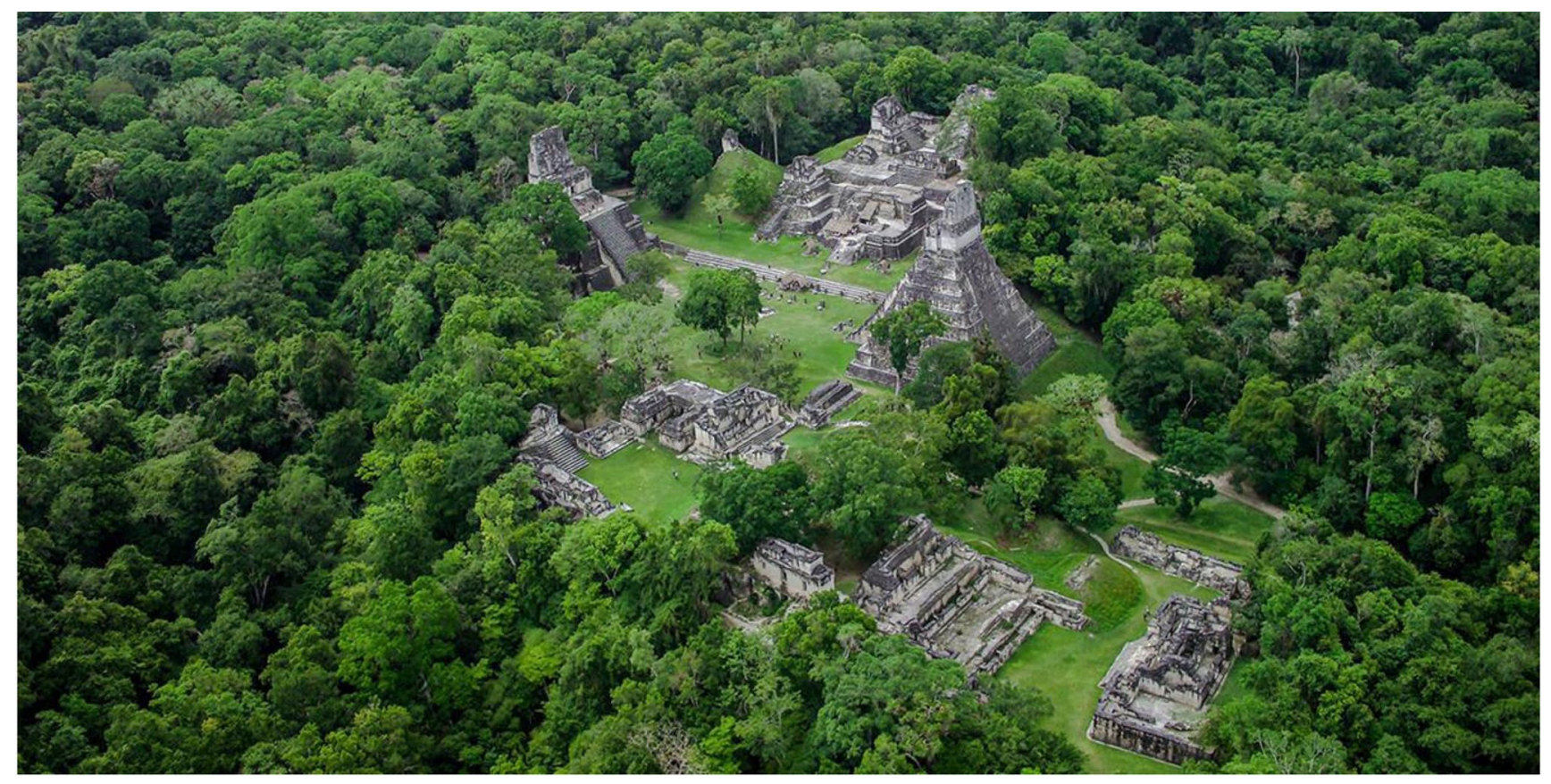

Lámina 1c. Vista aérea actual de Tikal.

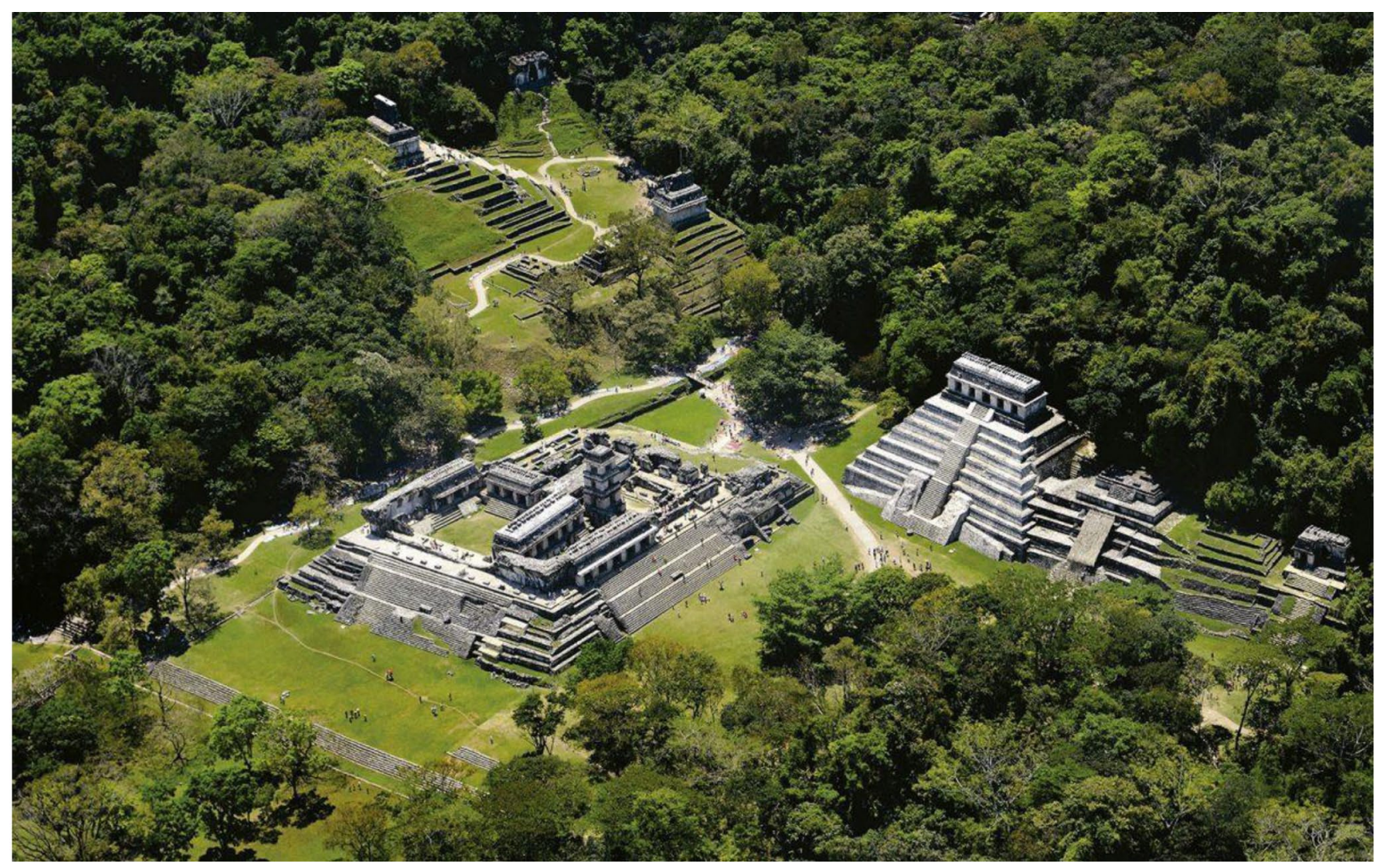

Lámina 1d. Vista aérea actual de Palenque. 
«El urbanismo, la arquitectura, la escultura y la pintura forman un todo integral e integrador que se configura como un mensaje idóneo de fuerza y poder (Uriarte, M.T.; 2012: 189)».

Todos los CA amerindios estaban planificados urbanísticamente y los edificios de culto más importantes se orientaban hacia los puntos cardinales (Láminas 2a, 2 b, 2c y 2d). Normalmente los ejes que siguen están marcados por el recorrido del sol, los solsticios y los equinoccios, para así llevar a cabo los rituales necesarios para controlar los ciclos naturales, a través del calendario, y ser favorecidos. Esto no solo se aprecia en las formas arquitectónicas de los TM y las diferentes estructuras donde se llevan a cabo los ritos y ceremonias; sino también en los relieves y las esculturas que acompañan a estos edificios, tanto en su disposición geográfica dentro del recinto, como en su iconografía (Carceller, 2010; Gussinyer, 1992-93: 183-230; López Austin, 1994; Sondereguer, 1989; Uriarte, 2012: 57-76: 57-76 y Vidal, 2002).

La arquitectura de estos TM cobra verdadero sentido gracias a la integración de la escultura y la pintura, convirtiéndose así en obras arquitecto-escultóricas con un fuerte simbolismo y atractivo, donde el color juega un papel fundamental a la hora de visualizar y comprender los edificios. Para poder entender la verdadera función y

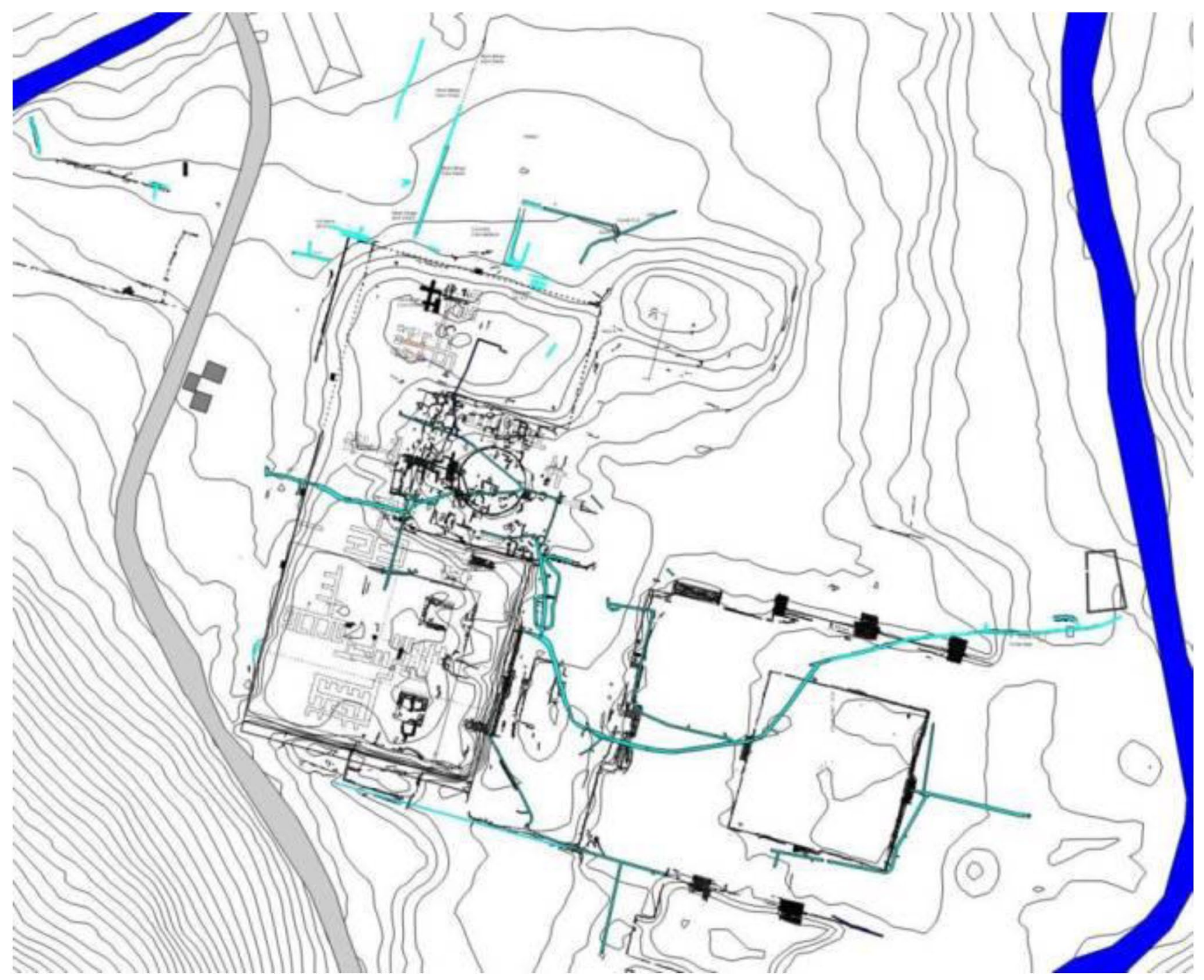

Lámina 2a. Plano-mapa de Chavín de Huántar y trayectoria de los canales subterráneos de agua estudiados por John Rick y el Proyecto Arqueológico Chavín de Huántar 


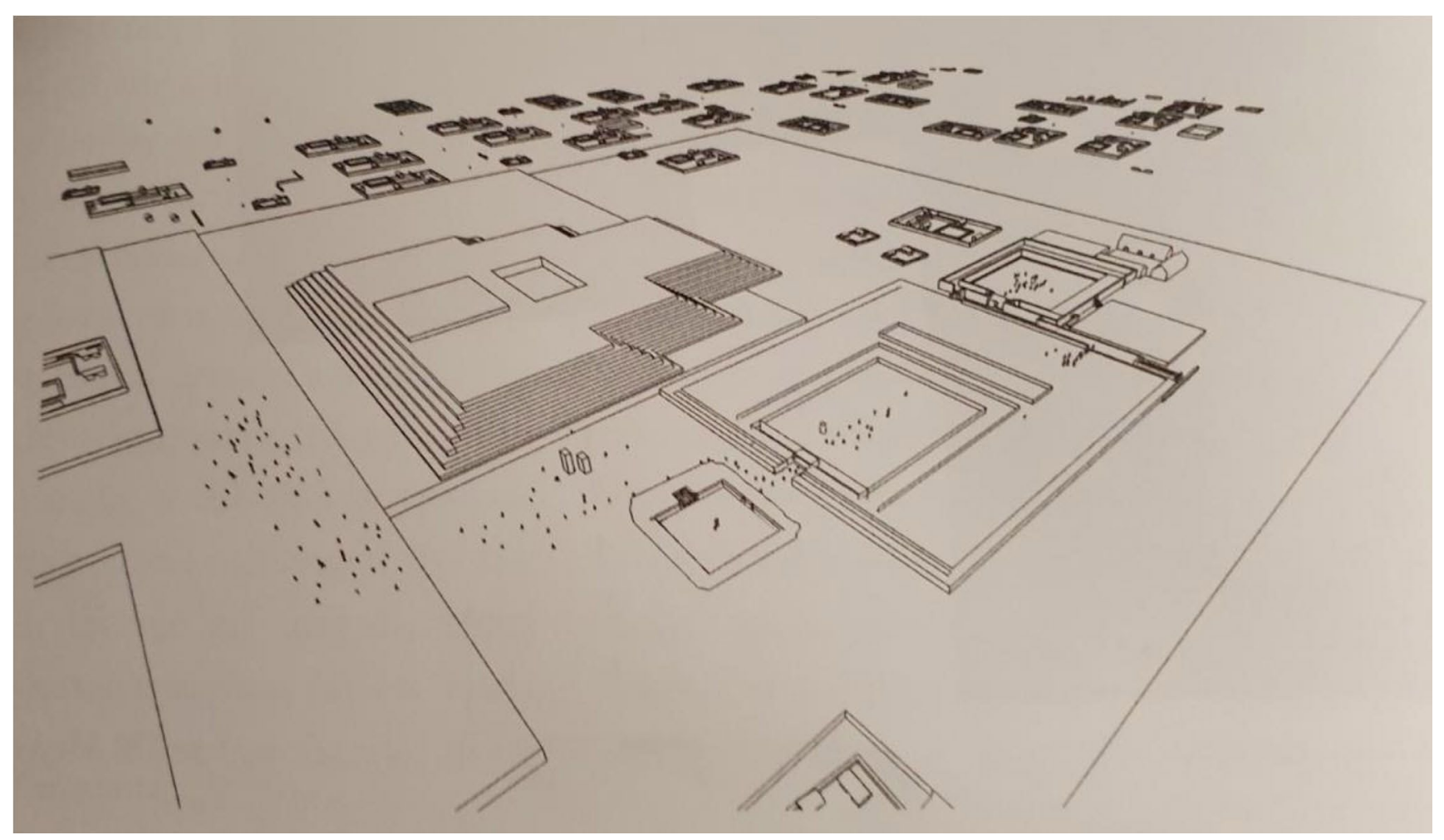

Lámina 2b. Reconstrucción-mapa del centro ceremonial de Tiahuanaco

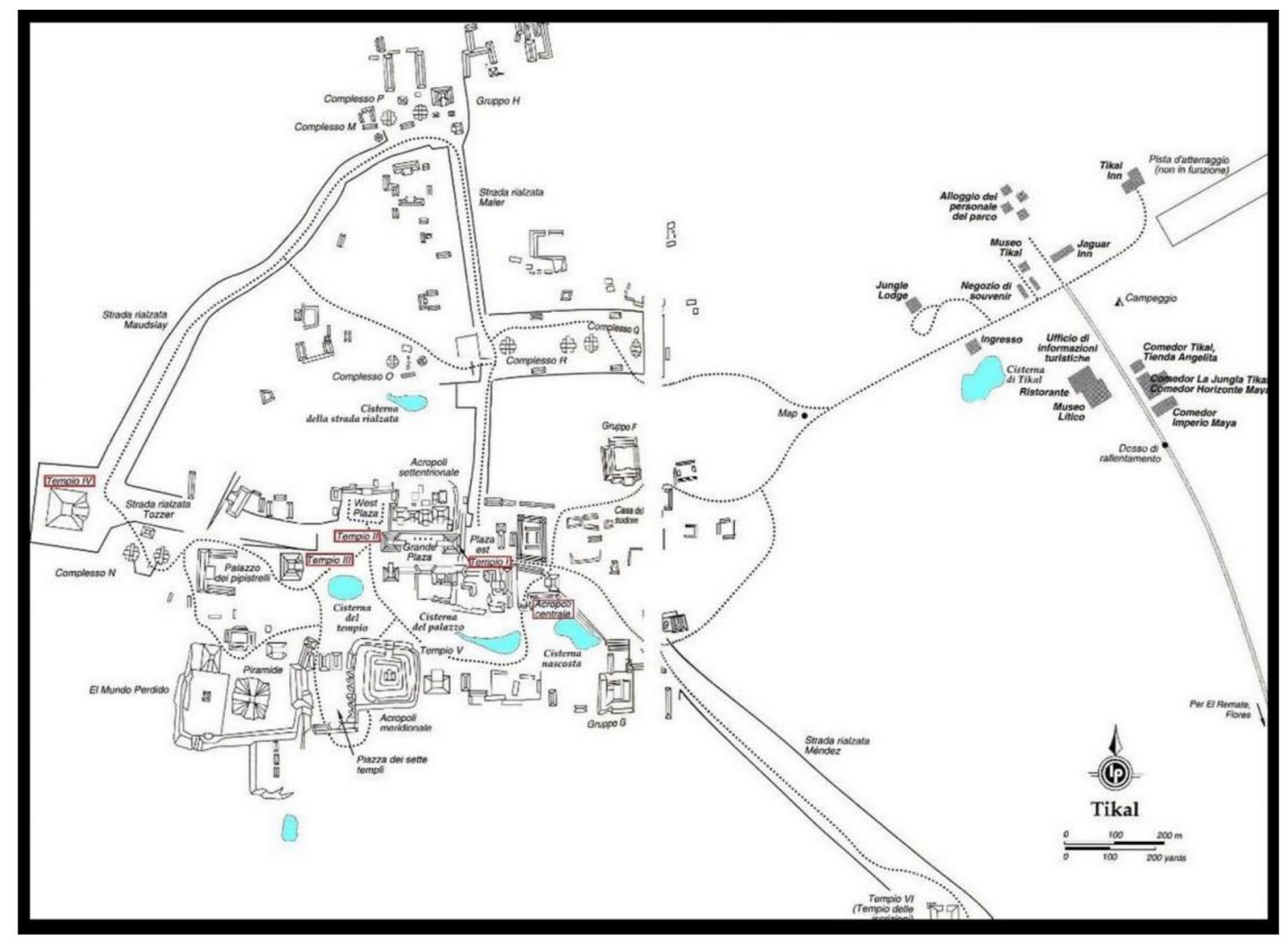

Lámina 2c. Mapa del centro ceremonial de Tikal, Petén 


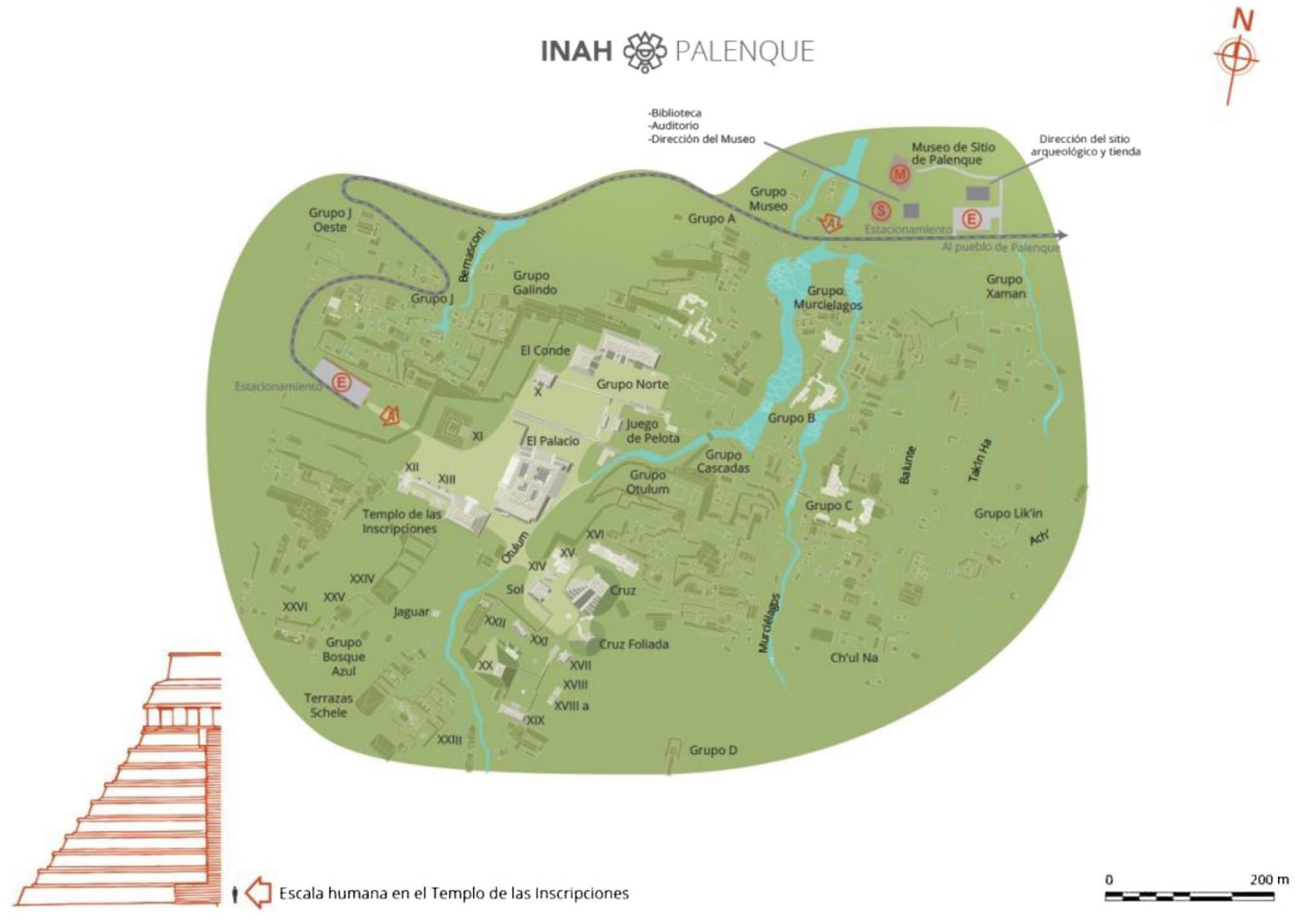

Mapa de la zona arqueológica de Palenque, Chiapas

finalidad de estos monumentos debemos tener en cuenta la fusión entre arquitectura, escultura y pintura (Barbier, 1997; Longhena, 2005: 122-125; López Austin y López Lujan, 1996; Sondereguer, 1998; Sondereguer, 2006; Uriarte, 2012 y Vidal, 2002).

\section{Zona andina: Chavín de Huántar}

El sitio de Chavín es considerado uno de los $\mathrm{CeC}$ principales dela zona andina. Algunos estudiosos creen que podría ser la "cultura madre" por su estilo panandino de fuerte tradición, expansión e influencia en culturas coetáneas y posteriores. Lo cierto es que Chavín es un lugar muy importante, ya que se construyó en el núcleo de convergencia entre varios caminos y se utilizó como observatorio astronómico, convirtiéndose en un lugar de peregrinaje y oráculo. El CoC estuvo en funcionamiento durante muchos años $y$, por ello, encontramos diferentes construcciones, ampliaciones y remodelaciones con estilos y materiales distintos (Alcina, 1991: 26-33; Barbier, 1997: 77-79; Bischof, 2012: 134-158; Campagno, 2007: 67-91; Carlson, 2012a: 3-28; Carlson, 2012b: 19-30;
Carlson, 2013: 2-18; Fux, 2012: 21-24; Lavallée, 1997: 168-204; López Austin y López Lujan, 1996; Lumbreras, 1993: 48-68 y 351-370; Lumbreras, 2012: 185-196; Mesía, 2012: 126-133; Rick, 2012a: 158-173; Rick, 2012b: 174-183; Sondereguer, 1998: 57-59; Sondereguer, 2006: 68-79 y Vidal, 2002).

En el CA de Chavín todo está planificado con anterioridad, bien definido y separado, con formas simples, monumentales, asimétricas y dinámicas. Los espacios sagrados, donde se llevaban a cabo los rituales están unidos a través de calles, plazas y templos, mostrando una gran originalidad a través de formas arquitectónicas cargadas de un fuerte simbolismo. En Chavín se encuentra una de las cerámicas mejor conservadas y de mejor calidad de los andes, al igual que los tejidos y los objetos metalúrgicos, y todas estas obras están decoradas con una rica iconografía que también se ve reflejada en la arquitecturaescultórica y la pintura (Bischof, 2012:134-158; Carlson, 2012a: 3-28; Carlson, 2012b: 19-30; Carlson, 2013: 2-18; Fux, 2012: 21-24; Lavallée, 1997: 168-204; Lumbreras, 1993: 48-68; Lumbreras, 2012: 185-196; Rick, 2012b: 174-183 y Sondereguer, 1998: 57-59). 
El Templo Antiguo o Viejo (TA-V) de Chavín puede considerarse un TM inicial (Lámina 3a). Éste tiene forma de $U$ y se encuentra enfrentado a una plaza circular hundida que también muestra esta dualidad amerindia del micro-macrocosmos y de lo masculino y lo femenino. En Chavín se siguen las tradiciones arquitectónicas de los andes: templo de plataformas bajas, anchas y macizas (creando mucha horizontalidad), con muros amplios y techos planos. Los muros de contención son gruesos y las piedras que forman el templo son grandes y bien talladas. El TA-V está repleto de galerías interiores y estructuras subterráneas (corredores y pasadizos) y un importante sistema hidráulico con canales de drenaje, claramente relacionados con los rituales que se llevaban a cabo allí. Por ello, al estudiar este edificio, no solo se ha de tener en cuenta la arquitectura visible, sino también la oculta porque el sonido y la visualización en sí del conjunto, templo, plaza y conectores (escaleras, senderos y rampas), muestran la verdadera función del CA (Lámina 3b). Además, en muchas de estas galerías y estancias subterráneas se han encontrado diferentes objetos religiosos (trompetas de caracola, espejos, cerámicas, bultos funerarios, objetos metálicos...) que remarcan aún más la importancia del lugar y su uso ritualístico (Alcina, 1991: 26-33; Bischof, 2012: 134-158; Carlson, 2012b: 19-30;
Lumbreras, 1993: 48-68; Mesía, 2012: 126-133; Rick, 2012a: 158-173; Rick, 2012b: 174-183 y Vidal, 2002).

En Chavín encontramos diferentes esculturas y relieves de periodos y estilos diferentes, pero todos con un estilo homogéneo, que cada vez es más complejo debido a los cambios en cuanto a la sofisticación del culto y las prácticas ceremoniales y la progresiva libertad artística. Se trata de un estilo geométrico, bidimensional y plano, poco realista pero con muchos detalles. La iconografía de Chavín destaca por sus seres híbridos de figuras humanas con rasgos felinos relacionadas con los dioses, ancestros y sacerdotes. Abundan los animales sagrados como el felino, la serpiente, las aves, los caimanes, las arañas... todos ellos símbolos de fuerza, poder y fertilidad. También encontramos representaciones de dioses, la mayoría con el distintivo ojo en doble ángulo y las mandíbulas felínicas (o los sacrificados sin cabeza). Estos dioses, ancestros y personajes destacados se relacionan con los ciclos naturales y suelen aparecer con motivos vinculados al poder, el agua y la tierra, como los báculos, el meandro escalonado y los espirales (Bischof, 2012: 134-158; Carlson, 2012a: 3-28; Carlson, 2012b: 19-30; Carlson, 2013: 2-18; Gutiérrez, 2003: 103-118; Lumbreras, 1993; Lumbreras, 2012: 185-196 y Rick, 2012a: 158-173).
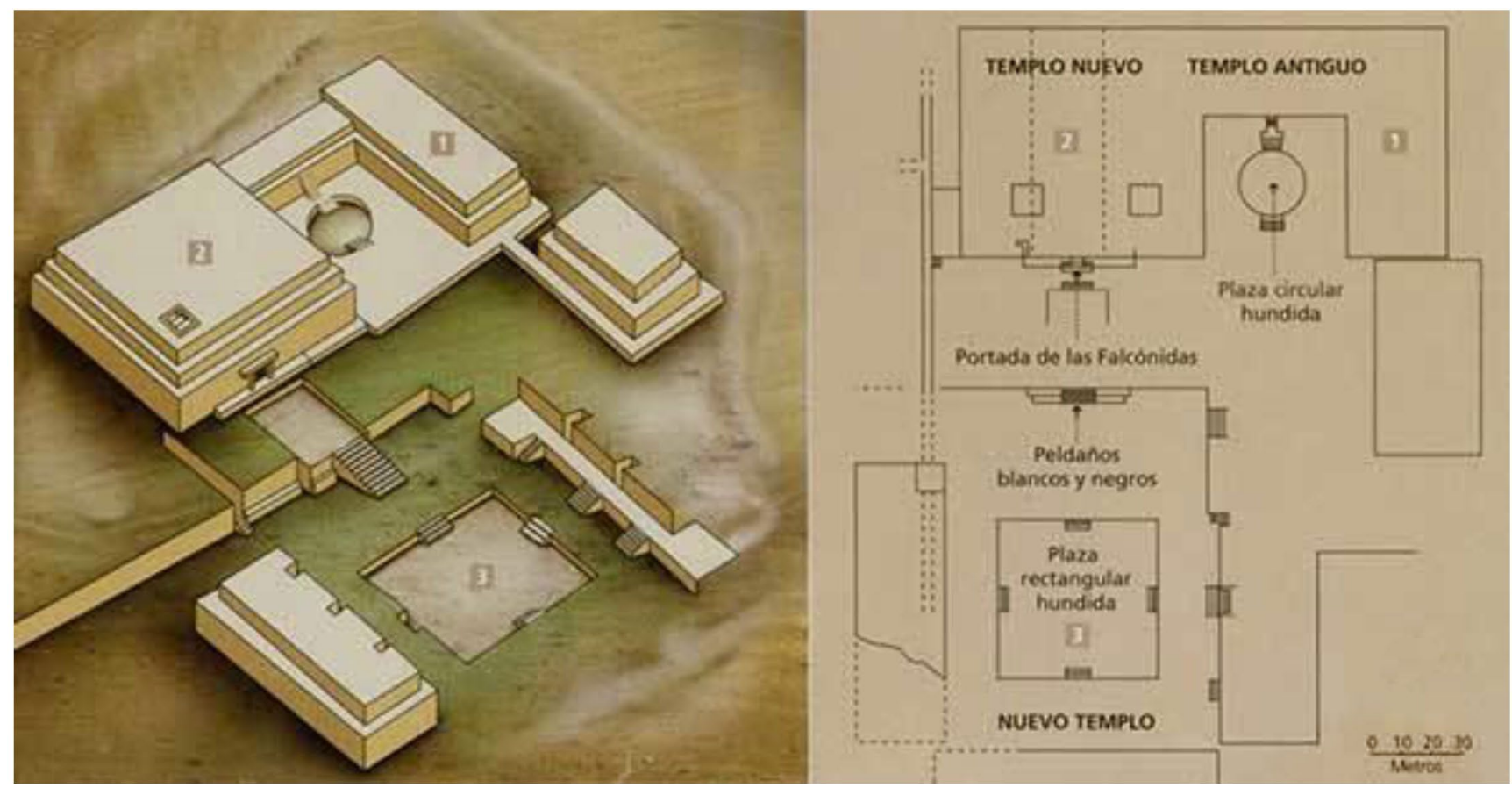

Lámina 3a. Plano y reconstrucción del TA-V de Chavín 


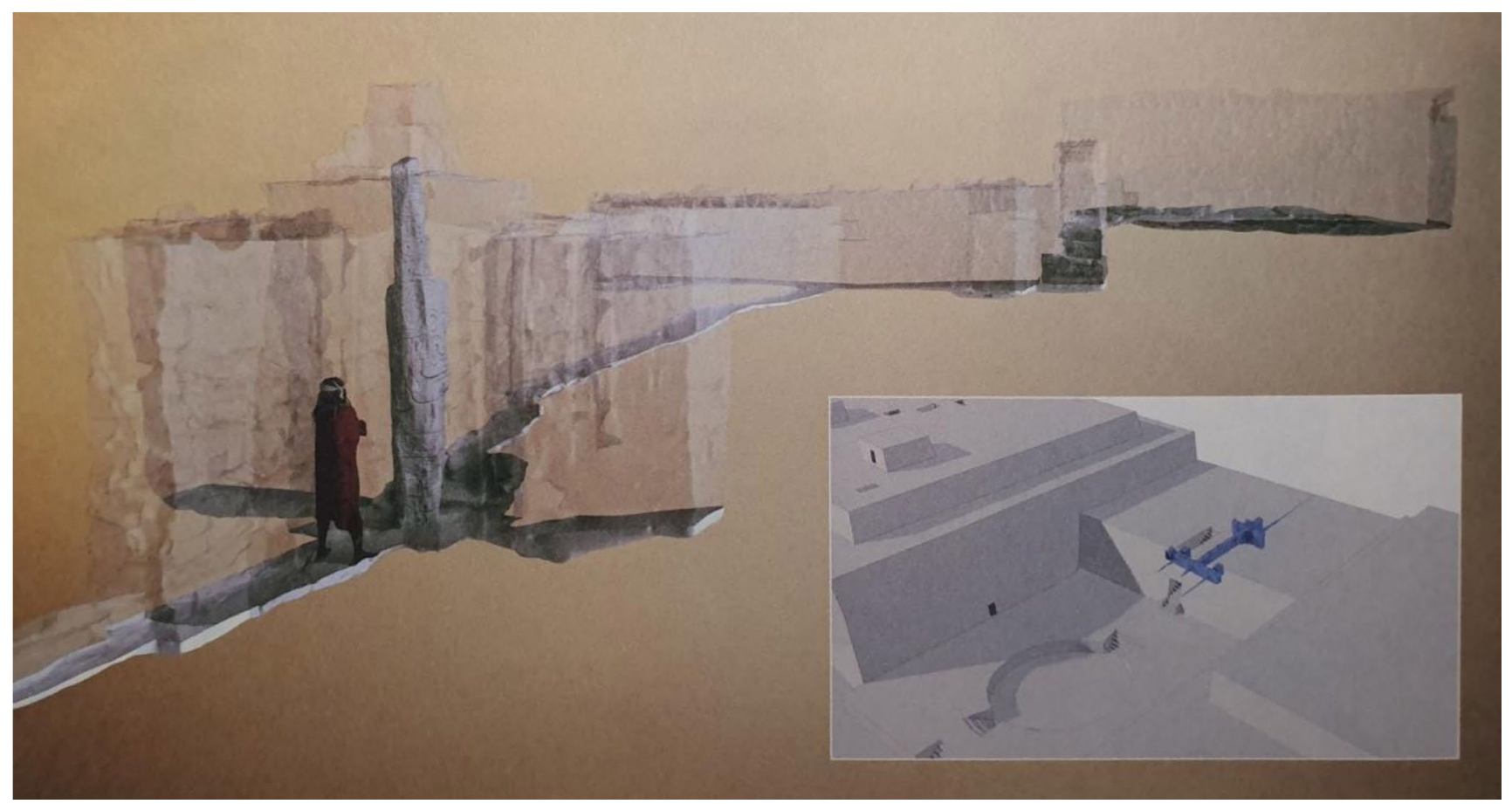

Lámina 3b. Reconstrucción de la Galería del Lanzón

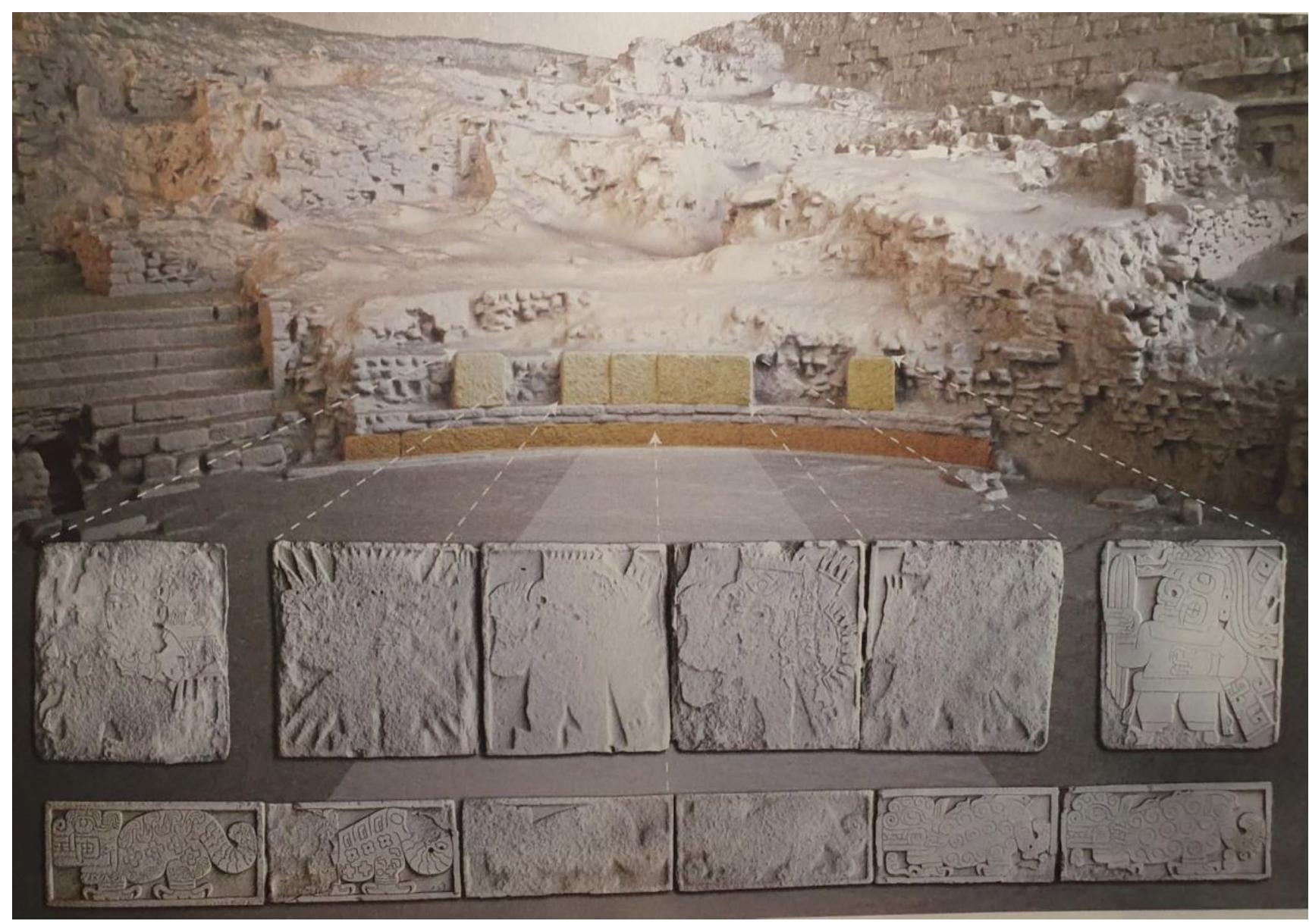

Lámina 3c. Relieves y reconstrucción de la Plaza circular hundida de Chavín 

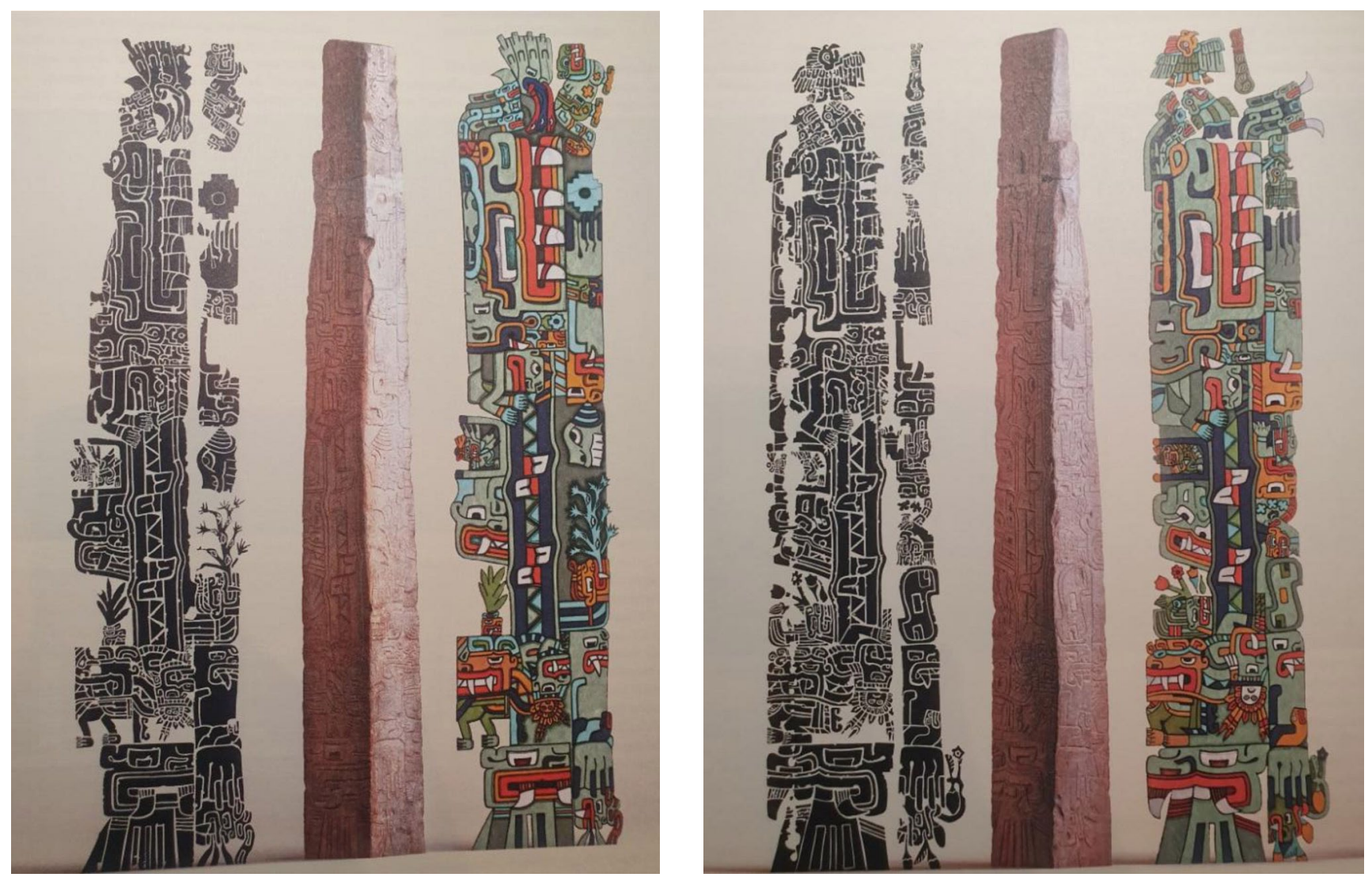

Lámina 3d. Obelisco Tello: dibujo y reconstrucción pictórica

En Chavín también encontramos cabezas clavas adosadas a los muros de los templos y/o las plazas principales, todas ellas con rasgos similares pero estilos diferentes. Como en las estelas y los monolitos, podrían ser la representación de ancestros o gobernantes (Alcina, 1991: 2633; Bischof, 2012:134-158 y Rick, 2012a: 158-173).

La plaza circular hundida (PCH) está decorada con unos relieves donde se representan a 28 seres antropomorfos con rasgos felínicos bailando portando diferentes objetos ritualísticos en las manos (Lámina 3c). Estos seres están orientados en 2 direcciones opuestas marcando la escalera principal de acceso al TA-V (occidental), y enfatizando el lugar más importante: la Galería del Lanzón (GL) (Alcina, 1991: 26-33; Bischof, 2012:134-158; Carlson, 2012b: 19-30; Lumbreras, 1993: 48-68 y Lumbreras, 2012: 185-196). Quizás, estas figuras también sirvan como una marca de la dirección de los rituales públicos que se llevaban a cabo en esta plaza hundida y la dirección hacia la GL remarque la importancia del sitio y el hecho de que sería el lugar donde acontecía el ritual privado al cual solo podían acceder los sacerdotes.

El Lanzón, primer ídolo de Chavín, es una escultura en forma de lanza con un relieve de un ser felínico situada en una pequeña cámara (ritual privado).Está perfectamente integrada en la habitación y presenta diferentes orificios y marcas que podrían estar relacionados con rituales de libación de líquidos. El ser está en trance, con los ojos hacia arriba y un gesto feroz, remarcando el hecho de ingerir sustancias psicotrópicas. En la cámara hay una pequeña abertura que deja pasar la luz e ilumina el rostro de este ser durante el solsticio de invierno, seguramente época en la que se realizaban los rituales más destacados. Esta escultura está relacionada con el TA-V de Chavín, situado en su interior, y con la iconografía de los relieves de la PCH (Carlson, 2012b: 19-30; Carlson, 2013: 2-18; Lumbreras, 1993: 48-68; Lumbreras, 2012: 185-196 y Rick, 2012a: 158-173).

Otra escultura destacada de Chavín es el Obelisco Tello (Lámina 3d). En él se ven dos criaturas draconianas, como dualidad de lo masculino y lo femenino, rodeadas de diferentes animales, creando así un horror vacui de difícil comprensión. Es posible que este obelisco se encontrase originalmente en el centro de la plaza circular y fuese una especie de aguja de un gran reloj solar que 
ilumina los diferentes relieves y así marcase el tiempo de los rituales que se llevaban a cabo en los diferentes ciclos agrícolas (Carlson, 2012b: 19-30; Carlson, 2013: 2-18; Janusek, 2005: 161-184; Lumbreras, 1993: 48-68 y Lumbreras, 2012: 185-196).

Otras de las estructuras subterráneas importante es la Galería de las Ofrendas. Se trata de una galería conectada por corredores y pasadizos donde el sonido, la iluminación y el flujo del aire crean una magia envolvente que reafirma la teoría de que allí se llevaban a cabo ceremonias muy destacadas. En su interior se han encontrado restos de animales, humanos, comida, líquidos y objetos foráneos (cerámica, jade, tejidos) que demuestran el contacto entre diferentes culturas y su utilización como lugar de peregrinaje y culto (Carlson, 2012b: 1930; Lumbreras, 1993 y Lumbreras, 2012: 185-196).

Toda la iconografía de Chavín se relaciona y expresa el mismo contenido religioso, pero con variaciones artísticas y estilísticas, debido a los años de uso del CeC y la progresiva complejidad de la religión y los rituales. Por ello, para poder entender el funcionamiento de este lugar, debemos tener en cuenta cada detalle de cada zona del CA y establecer las relaciones entre las diferentes piezas, independientemente del periodo al que pertenecen (Bischof, 2012: 134-157, Carlson, 2012a: 3-28; Carlson, 2012b: 19-30; Carlson, 2013: 2-18 y Rick, 2012b: 174-183).

\section{Zona andina: Tiahuanaco}

Otro CeC andino destacado es el sitio de Tiahuanaco (Lámina 4a); que albergó una de las culturas amerindias más longevas y fue un Estado religioso que se expandió y conquistó todo el valle del Titicaca, convirtiéndose en un lugar de peregrinaje por excelencia. Una ciudad venerada por los incas que está rodeada por un gran lago artificial, creando así una visión mítica del territorio, a modo de cosmograma y Montaña Primogénita que, al extenderse tanto en el tiempo, se desarrolló urbanísticamente de forma desigual. Al sufrir remodelaciones, superposiciones y reutilizaciones de estructuras, de las cuales hoy en día solo quedan algunos vestigios, su comprensión es difícil (Berenguer, 2000: 7-47 y 95-100; Brughetti, 2000: 7-14; Campagno, 2007: 67-91; Janusek, 2010: 1-19; Kolata, 2004: 96-125; López Austin y López Lujan, 1996; Manzanilla, 1992: 15-20; Vranich, 2009: 11-34; Vranich, 2010: 1-11 y Young, 2004: 24-40).

La arquitectura de Tiahuanaco es monumental y eterna, con formas proporcionadas y simétricas. Está hecha de adobe y piedra maciza bien tallada y aparejada, pero, debido a los saqueos masivos y la reutilización, gran parte de los edificios se han destruido. En Tiahuanaco se crea un contraste de colores bellísimo, ya que las piedras utilizadas tienen una policromía natural muy llamativa: la andesita es gris-azulada y la arenisca es roja. Además, se conservan restos de estuco pintado y relieves policromados en algunas partes (Alcina, 1991: 64-65; Barbier, 1997: 82-84; Brughetti, 2000: 7-14; Hoopes, 2009: 247-272; Janusek, 2010: 1-19; Kolata, 2004: 96-125; Lavallée, 1997: 168-204; López Austin y López Lujan, 1996; Makowski, 2010: 1-17; Manzanilla, 1992: 15-20 y 35-41; Sondereguer, 1998: 59-60; Sondereguer, 2006: 68-79; Vidal, 2002; Vranich, 2009: 11-34; Vranich, 2010: 1-11 y Young, 2004: 24-40).

Pese a la reutilización progresiva del CA, en Tiahuanaco se ve claramente que todo está planificado urbanísticamente de forma centralizada y con una orientación cardinal que sigue el recorrido solar. La ciudad es cuadripartita y sigue dos ejes, el N-S y E-O y el eje equinoccial E-O, uniendo los monumentos más importantes (Lámina 4b): el Templo de Kalasasaya (TK), el Templo Semisubterráneo (TSS), la Pirámide de Akapana (PA) y la Pirámide de Puma Punku (PPP) (Janusek, 2010: 1-19; Kolata, 2004: 96-125; Vidal, 2002 y Young, 2004: 24-40).

En Tiahuanaco se siguen tradiciones arquitectónicas andinas con pirámides de terrazas superpuestas, patios hundidos, templos en U y estructuras subterráneas. Al mismo tiempo se crean nuevos espacios: las grandes portadas y las escaleras y caminos de unión de los diferentes lugares de culto. En la escultura se realizan piezas tradicionales, como las cabezas clavas, pero se innova con los monolitos y las estelas (Alcina, 1991: 64-65; Barbier, 1997: 82-84; Brughetti, 2000: 7-14; Janusek, 2010: 1-19; Kolata, 2004: 96-125; Lavallée, 1997: 168-204; Manzanilla, 1992: 104-106; Sondereguer, 2006: 68-79; Vidal, 2002; Vranich, 2009: 11-34; Vranich, 2010: 1-11 y Young, 2004: 24-40).

La PA es el monumento más importante dentro del CA de Tiahuanaco. Está situada en el centro de la ciudad y consta de 7 terrazas superpuestas. Su forma de $1 / 2 \mathrm{cruz}$ andina con 3 esquinas salientes remarcan la sofisticación de la planta. En la cima hay un patio hundido, diferentes zonas de culto en el $\mathrm{N}$ y en el $\mathrm{S}$, y residencias sacerdotales. En occidente está la escalinata de acceso principal. Los muros son de arenisca y están revestidos con losas horizontales de sillería rectangular. Los muros de contención son gruesos y las cornisas están decoradas con pilares, esculturas de basalto, cabezas clavas y motivos 
que hacen referencia al dios Viracocha y a animales sagrados como el puma y el cóndor. En la cima de la PA se han encontrado restos de grava azul-verde y se cree que podría ser una imitación de los picos de las montañas que rodean el CA, convirtiendo este TM en una alegoría de la MS. Toda la pirámide está compuesta por complejos sistemas hidráulicos hechos con materiales impermeabilizantes, convirtiendo la pirámide en una gran fuente, donde el agua y el sonido juegan un papel muy importante a la hora de entender el edificio y los rituales llevados a cabo en él ${ }^{3}$. La PA es el edificio más grande del CeC de Tiahuanaco y es el lugar donde se realizan los rituales más importantes debido a la magnífica visualización y relación que se tiene con el paisaje y las montañas del sitio. La PA es un símbolo de fertilidad, abundancia y destrucción. Es vida y muerte, crecimiento y regeneración
(Berenguer, 2000: 7-9; Hoopes, 2009: 247-272; Janusek, 2010: 1-19; Kolata, 2004: 96-125; Lavallée, 1997: 168204; Manzanilla, 1992: 21-45 y 107-109; Vranich, 2001: 295-308; Vranich, 2009: 11-34 y Young, 2004: 24-40). Al N de la PA está el TSS. Se trata de un edificio cuadrado hundido con una escalinata descendiente de 7 peldaños, todo construido con sillares toscos de arenisca roja. En la pared principal del templo hay 175 cabezas clavas y, en el centro del patio, 4 estelas, uno de ellos el Monolito Bennett (Berenguer, 2000: 11-12; Kolata, 2004: 96-125; Lavallée, 1997: 168-204; Vranich, 2009: 11-34 y Young, 2004: 24-40). Al E del TSS encontramos el TK. Este monumento está construido con sillares bien tallados y aún conserva la gran escalinata de 7 peldaños y la puerta monumental orientada al sol naciente (Puerta del Sol). Consta de un muro en forma de $\mathrm{U}$, un patio hundido con 7

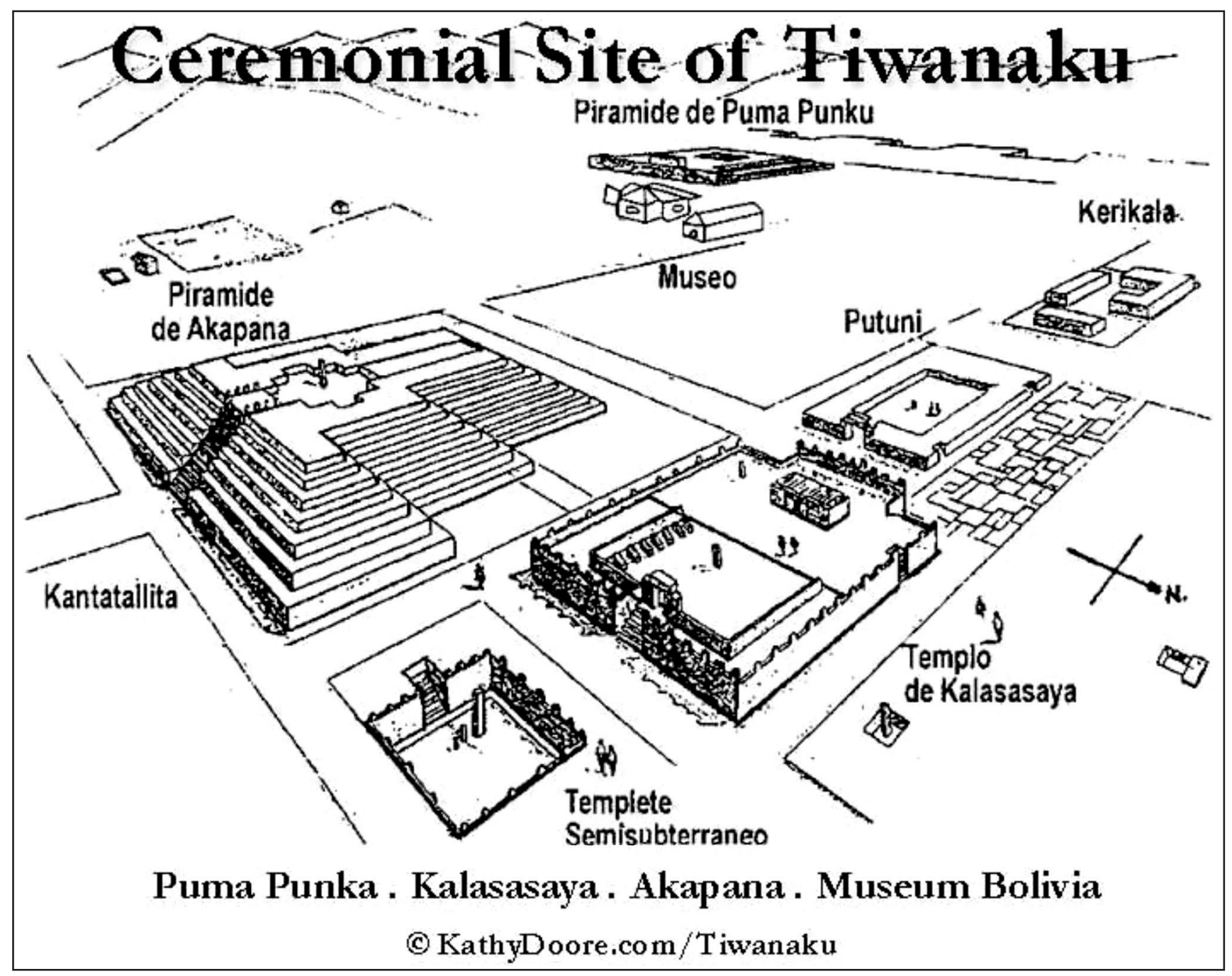

Lámina 4a. Reconstrucción del centro ceremonial del sitio de Tiahuanaco 


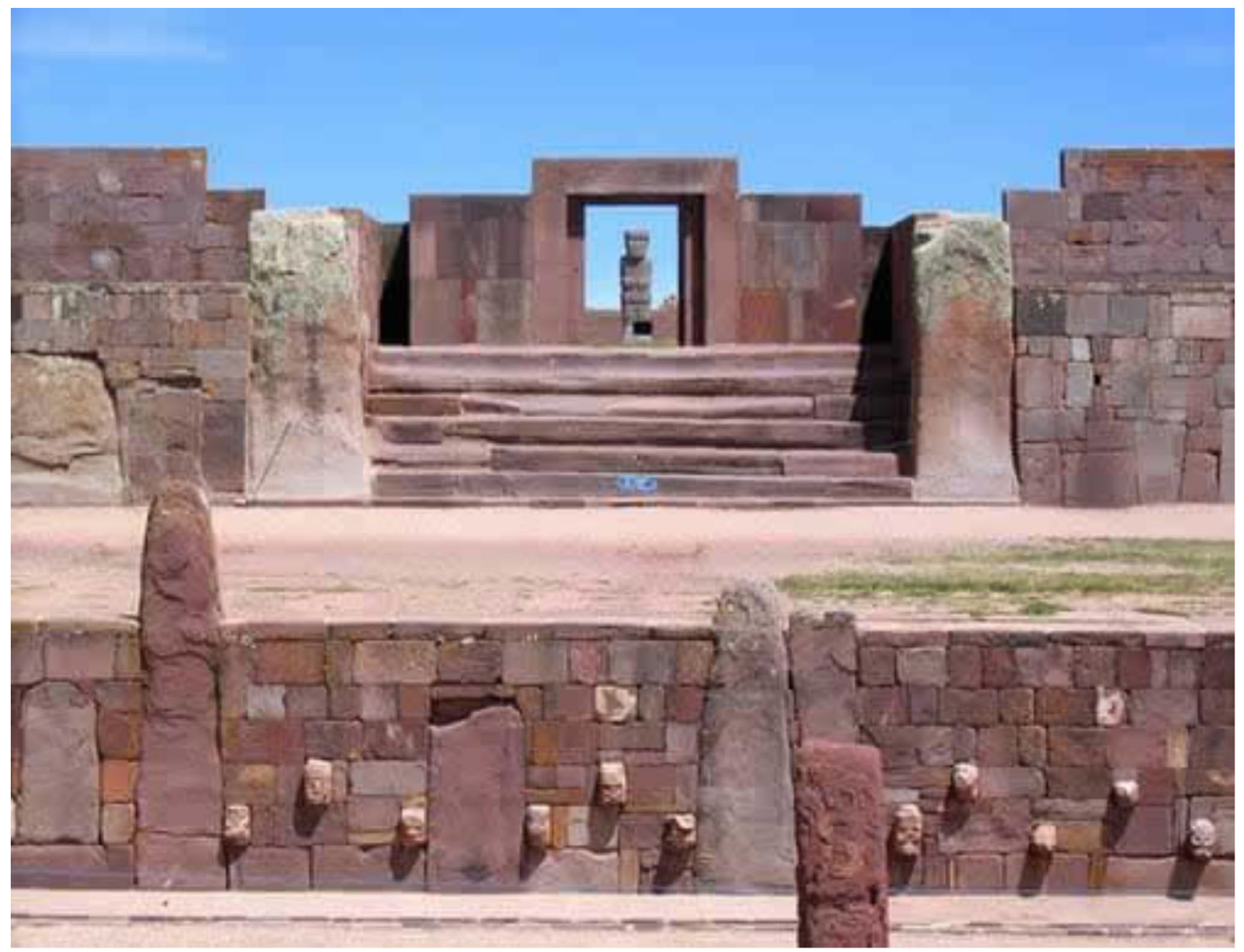

Lámina 4b. Vista del Templo de Kalasasaya y el Templo Semisubterráneo de Tiahuanaco

cámaras subterráneas ${ }^{4}$ y 11 pilares gigantes de arenisca roja y andesita, junto a los monolitos Ponce y el Fraile ${ }^{5}$ (Berenguer, 2000: 13-15; Brughetti, 2000: 7-14; Janusek, 2010: 1-19; Kolata, 2004: 96-125; Lavallée, 1997: 168-204; Vranich, 2009: 11-34; Vranich, 2010: 1-11 y Young, 2004: 24-40). Delante de la PA está la PPP, una pirámide de planta rectangular con 2 brazos orientales en forma de T, compuesta por 3 terrazas superpuestas. Está construida con sillares de arenisca roja y argamasa de arcilla, cal y arena fina. En occidente hay una escalinata que lleva a la cima, aplanada y en forma de U recubierta con capas rojas y con un patio hundido con una capa verde, y al TS acompañado de diferentes estructuras ${ }^{6}$.
En este edificio también hay un sistema hidráulico que convierte la pirámide en una gran fuente. La PPP podría ser la pareja dual de la PA o una construcción posterior para la élite (Berenguer, 2000: 21-26; Kolata, 2004: 96125; Lavallée, 1997: 168-204; Vranich, 2009: 11-34 y Young, 2004: 24-40).

La iconografía de Tiahuanaco sigue 4 principios básicos: simetría, repetición, reducción de las figuras y reducción del espacio a 2D, usando la bidimensionalidad para los seres míticos y la tridimensionalidad para los personajes reales. En Tiahuanaco se encuentran algunos paralelismos con Chavín en cuanto a la disposición de las figuras de forma recargada y la abundancia de felinos,

3 En la PA se han encontrado innumerables ofrendas y sacrificios, tanto humanos como animales. La PA sería el lugar de culto más destacado dentro de Tiahuanaco y estos restos remarcarían el papel que desempeñó el edificio y los períodos complicados que vivieron los residentes de CoC (Manzanilla, 1993). 


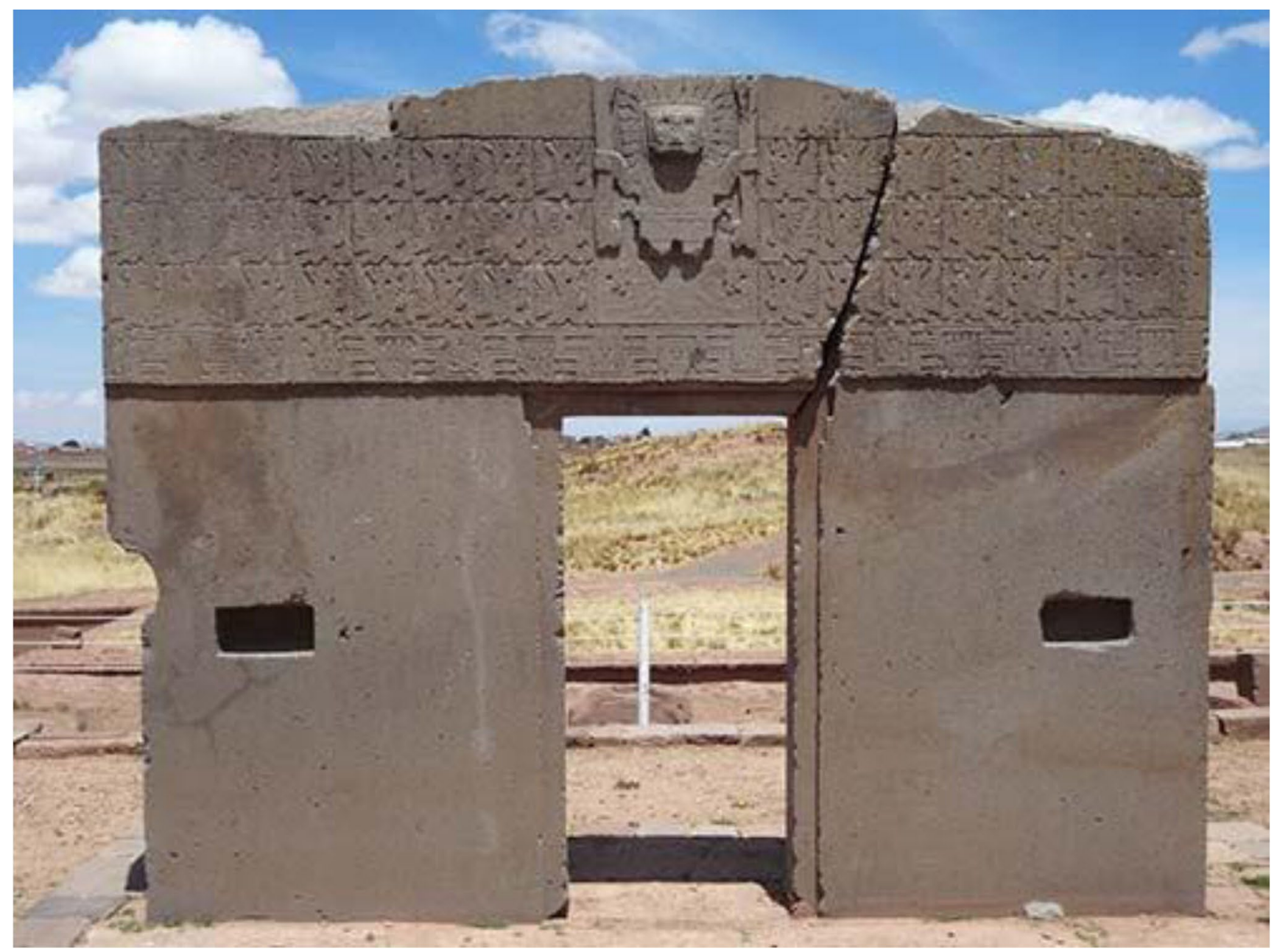

Lámina 4c. Puerta del sol de Tiahuanaco

aves, serpientes, peces y otros motivos relacionados con la fertilidad y el poder; pero se introducen nuevas figuras humanas (dioses, ancestros, sacerdotes y gobernantes) y signos calendáricos. Además, las escenas dejan de ser estáticas y se crean representaciones en movimiento, quizás rituales practicados. También encontramos diferentes piezas cerámicas, metalúrgicas y textiles, todas con una iconografía rica y de difícil comprensión. En ellas se aprecia un cambio estilístico, ya que se pasa de un arte realista, naturalista y expresivo a uno más geométrico, esquemático y simplificado, marcando las diferentes etapas y complicando su comprensión (Alcina, 1991: 64-65; Brughetti, 2000: 7-14; Clados, 2009: 101-114; Conklin, 2009: 115-132; Gutiérrez, 2003: 103-118; Hoopes, 2009: 247-272; Janusek, 2010: 1-19; Kolata, 2004: 96-125; Makowski, 2009: 133-164; Makowski, 2010: 1-17 y Zuidema, 2009: 83-100).

Las obras escultóricas más destacadas de Tiahuanaco son la Puerta del Sol (PDS), el Monolito Ponce (MPo), el monolito Bennett (MB) y el monolito El Fraile (MF) (Láminas 4c, 4d, 4e, y 4f), las cuales representan el calendario tiahuanacota y podrían ser marcas

4 Estas cámaras subterráneas podrían ser mausoleos de ancestros y antepasados porque se han encontrado restos humanos en algunas zonas y porque, posteriormente, los incas tenían estas tradiciones funerarias (Berenguer, 2000).

5 Los pilares podrían ser la representación del calendario tiahuanacota y una marca astronómica y astrológica relacionada con el recorrido del sol dentro del CeC utilizado para controlar el tiempo y propiciar los rituales (Kolata, 2004: 96-125).

6 En la PPP se han encontrado relieves en los muros y bajorrelieves en las puertas y los dinteles, pero su estado de conservación no permite apreciar bien las figuras. 


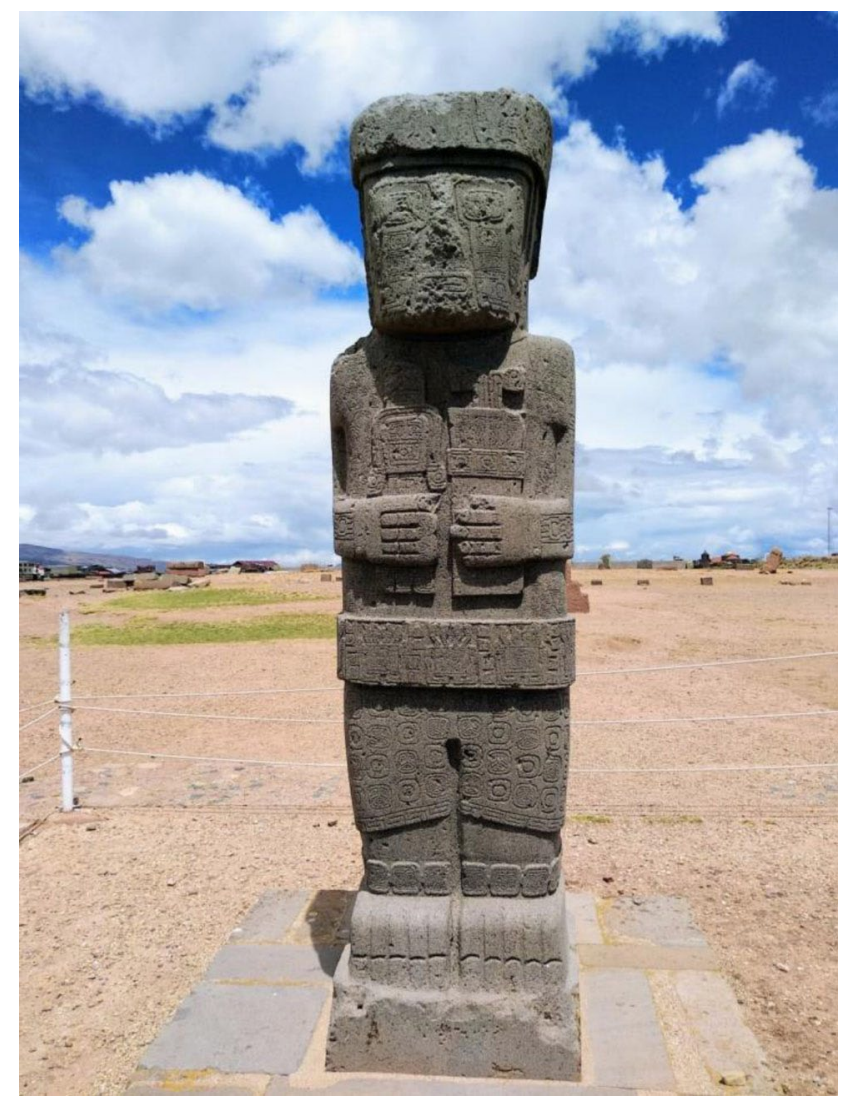

Lámina 4d. Monolito Ponce

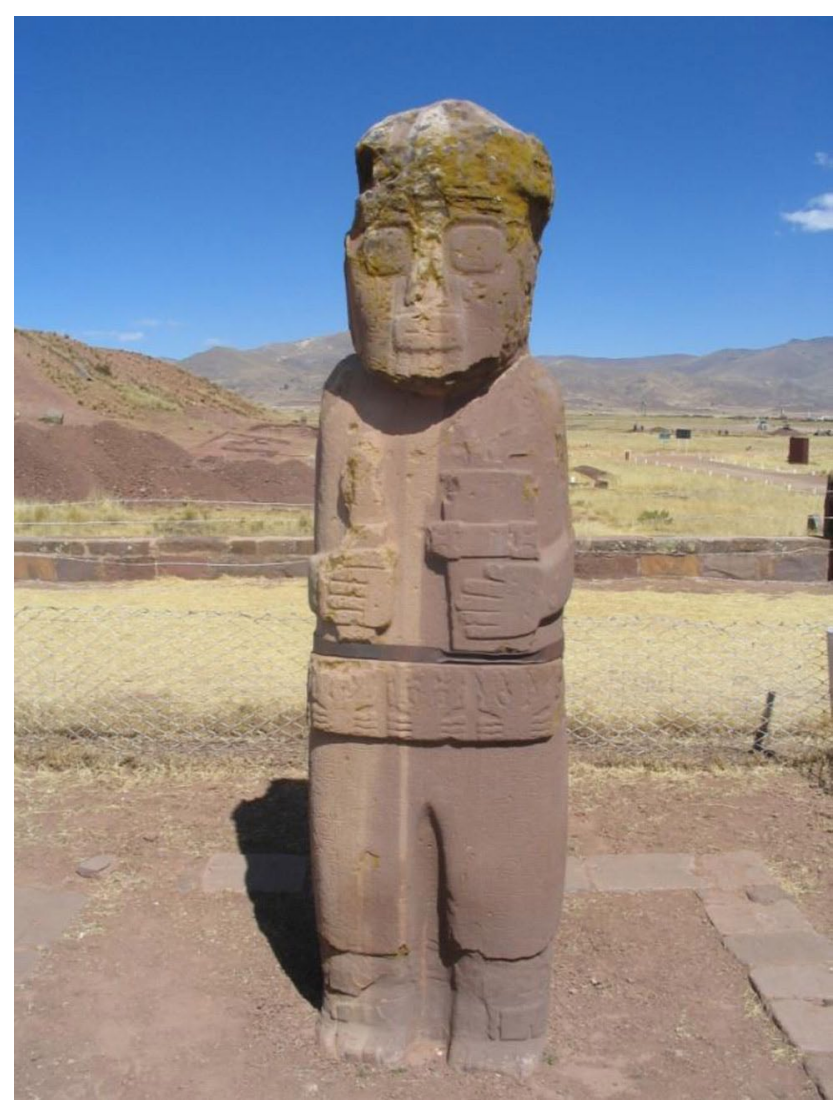

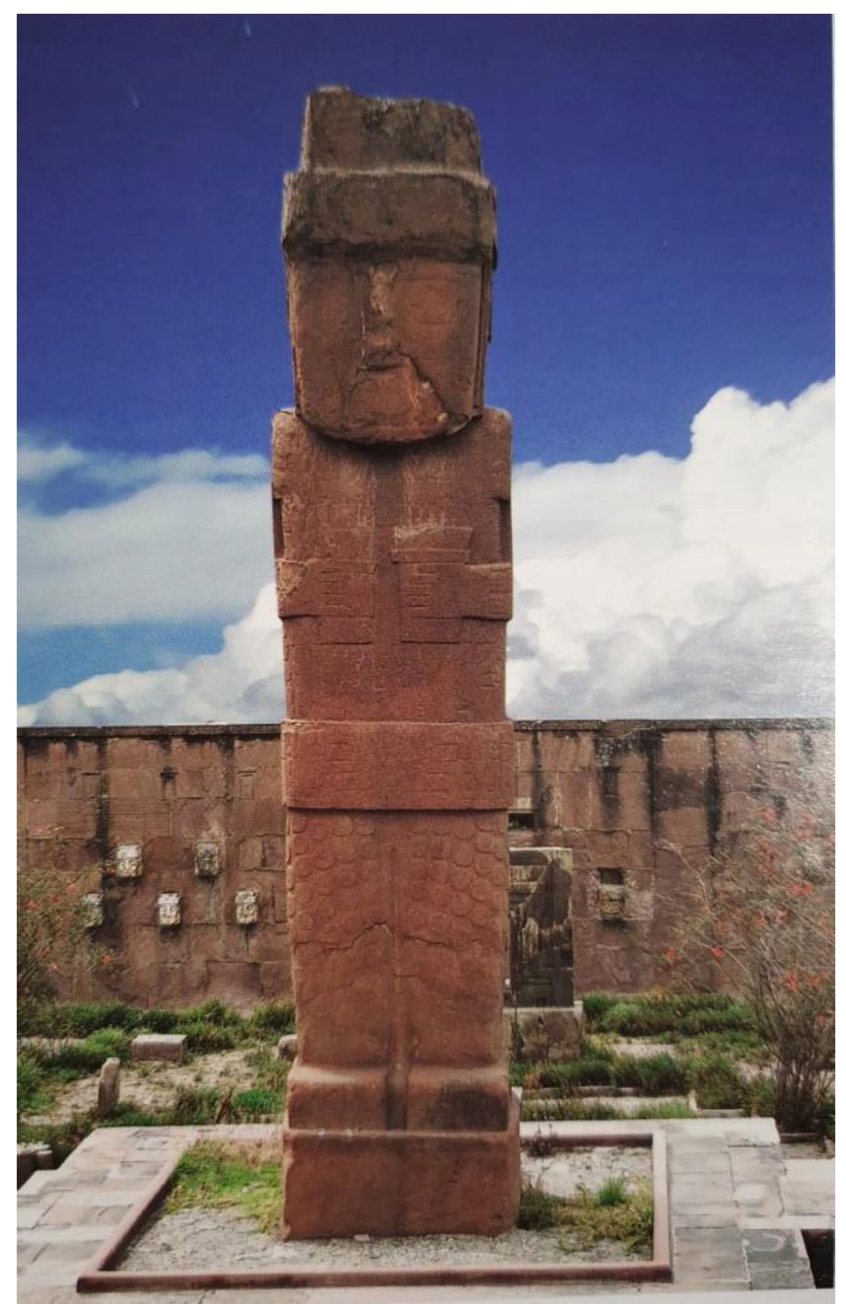

Lámina 4e. Monolito Bennett 
astronómicas de los ciclos calendáricos y guías de los rituales y procesiones que se hacían en el CA (Berenguer, 2000: 34-36; Clados, 2009: 101-114; Conklin, 2009: 115-132; Gutiérrez,2003: 103-118; Hoopes, 2009: 247-272; Kolata, 2004: 96-125; Makowski, 2009: 133164; Makowski, 2010: 1-17; Manzanilla, 1992: 104-106 y Zuidema, 2009: 83-100).

Para poder entender la iconografía y la disposición de los monumentos de Tiahuanaco es fundamental comprender su calendario y los diferentes ciclos astronómicos. El calendario es lo que ordena el espacio sagrado, el tiempo y los diferentes monumentos, mediante zonas públicas y privadas grandes y expansivas donde se llevaban a cabo los rituales. Y, gracias a la fusión entre la arquitectura y la escultura, se transmiten los mensajes cosmogónicos y políticos más importantes (Benítez, 2009: 49-82; Berenguer, 2000: 27-33; Clados, 2009 : 101-114; Conklin, 2009: 115-132; Hoopes, 2009: $247-$ 272; Kolata, 2004: 96-125; Makowski, 2009: 133-164; Vranich, 2009: 11-34; Vranich, 2010: 1-11 y Zuidema, 2009: 83-100).

\section{Mesoamérica: Tikal}

Tikal es la ciudad maya más grande e importante del período clásico. Tiene más de 3000 monumentos, entre los cuales destacan el Templo 1 (T1) o del Gran Jaguar, el
Templo 2 (T2) o de las máscaras y la Gran Plaza ceremonial (GP) con estelas (Lámina 5a). La planificación urbanística del CeC se ve interrumpida por la superposición y reconstrucción de edificios, pero tiene una orientación $\mathrm{N}-\mathrm{S}$ que sigue el recorrido del sol. Todos los edificios están distribuidos alrededor de patios y plazas, creando un espacio escénico propicio para la visualización del entorno y de las ceremonias celebradas. Se trata de una ciudad construida entre 2 barrancos, con varios estanques y edificaciones que sobresalen, convirtiéndose así en una metrópoli dentro de la selva donde la arquitectura se fusiona con la naturaleza (Aimi, 2003: 84-85; Alcina, 1991: 52-53; Barbier, 1997; Campagno, 2007: 39-66; Carceller, 2010: 58-61; Domenici, 2007: 58-61; Longhena, 2005: 242-251; López Austin y López Lujan,1996; Marquina, 1981: 535-557; Muñoz, 1999a: 25-30; Muñoz, 1999b: 43-50; Olmedo, 1998: 9-100; Sondereguer, 1989: 36-38; Sondereguer, 1998: 38-39; Sondereguer, 2006: 33-34; Stierlin, 1997: 104-167; Stierlin, 2001; Vidal, 1999a: 19-24 y Vidal, 2002).

La arquitectura de Tikal es monumental, colosal, simétrica y de volúmenes pesados. Los muros son gruesos y, gracias al uso de las matemáticas y la astronomía, se siguen los principios de morfoproporcionalidad, creando formas geométricas casi perfectas. Los TM tienen un basamento escalonado muy grande, vertical y monumental con el uso del talud y una escalinata axial, que divide

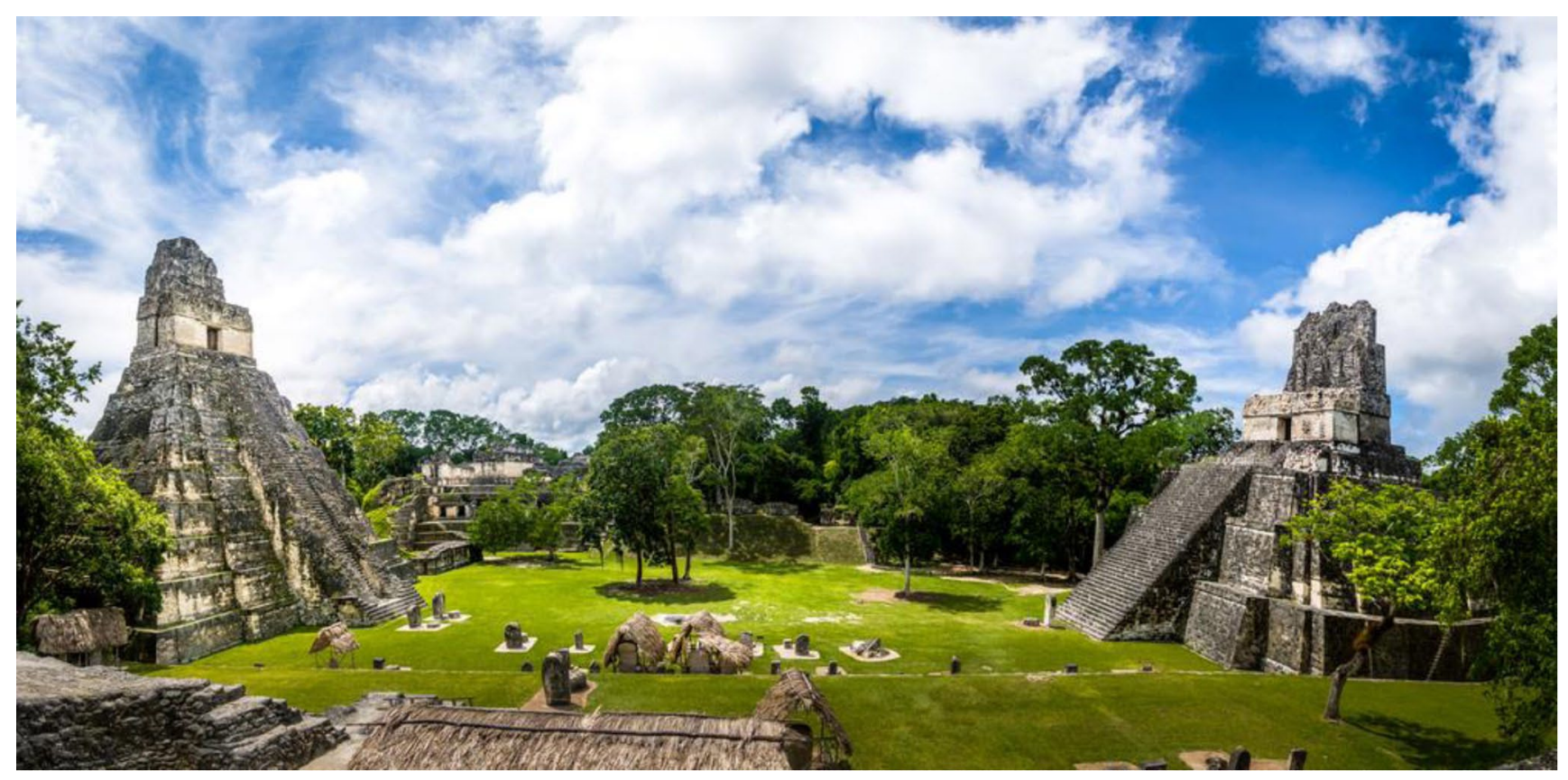

Lámina 5a. Vista actual del centro ceremonial de Tikal 


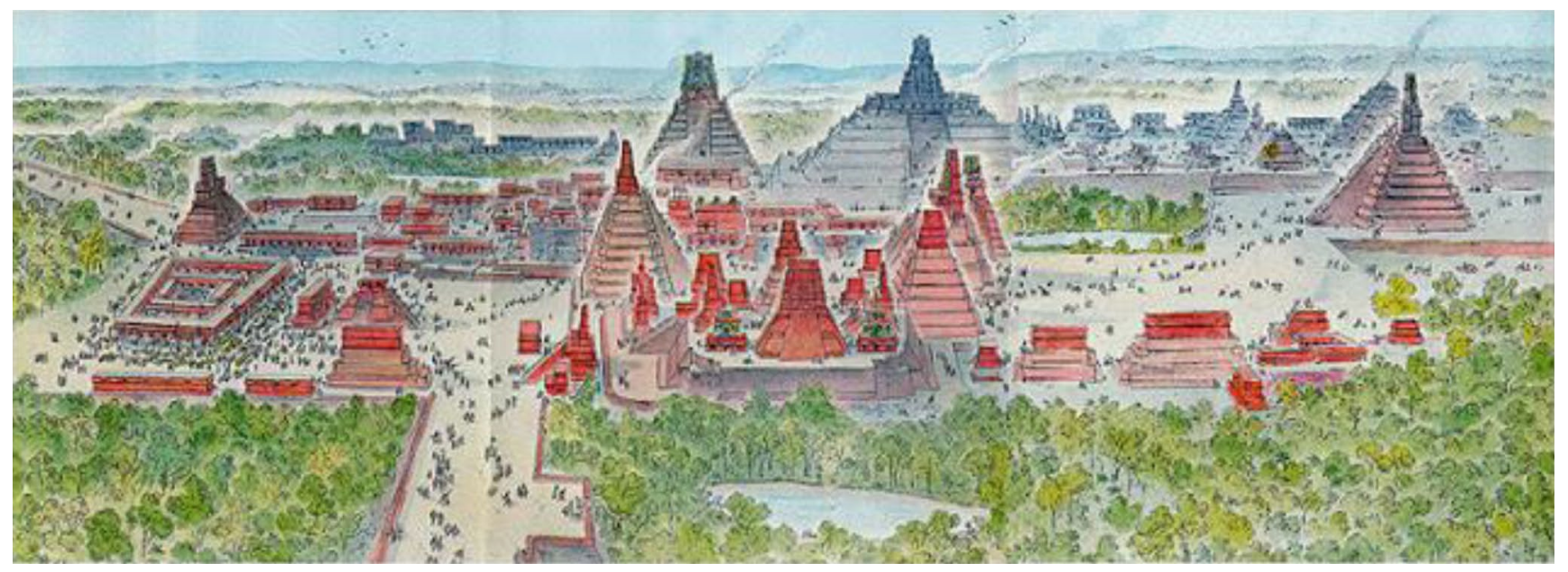

Lámina 5b. Reconstrucción del centro ceremonial de Tikal - vista panorámica de la ciudad

el TM. El TS es pequeño, solo tiene una puerta, está cubierto con bóvedas falsas y recubierto con un gran friso decorado e inclinado rematado con una gran crestería maciza (AAVV; 2002: 60-101; Alcina, 1991: 52-53; Barbier, 1997; Carceller, 2010: 58-61; Domenici, 2007: 7681 y 110-114; Longhena, 2005: 242-251; López Austin y López Lujan, 1996; Marquina, 1981: 535-557; Muñoz, 1999a: 25-30; Muñoz, 1999b: 43-50; Olmedo, 1998: 9-100; Piña y Matos, 1998: 141-225; Quintana, 1999: 77-82; Sondereguer, 1989: 36-38; Sondereguer, 1998: 38-39; Sondereguer, 2006: 33-34 y 61-67; Stierlin, 1997: 104-167; Stierlin, 2001: 35-56; Uriarte, 2012: 116-119 y Vidal, 2002).

«Un templo piramidal maya contemplado a una cierta distancia constituye una unidad escultórica perfectamente armónica». (Alcina, J.; 1991: 48)

Los relieves escultóricos de Tikal son bidimensionales y están dispuestos en franjas horizontales. Las estelas y los dinteles (de piedra y madera), los altares y los mascarones muestran figuras humanas con siluetas precisas, muy frontales y hieráticas. Representan gobernantes, ancestros, dioses y animales, glifos calendáricos y símbolos de poder. Se han encontrado restos de policromía en paredes de templos, estelas, dinteles y altares, creando una visión colorida del CoC (Lámina 5b), muy distinta de la actual (Barbier, 1997; Domenici, 2007: 76-81; Piña y Matos, 1998: 141-225; Sondereguer, 1998: 38-39; Sondereguer, 2006: 33-34 y 61-67; Stierlin, 1997: 104-167 y Uriarte, 2012: 119-122).

El T1 y el T2 son los templos más destacados de Tikal' El T1 es la pirámide más vertical y ascendente de toda Mesoamérica (Lámina 5c). Es un TM de 9 cuerpos $^{8}$ superpuestos con una enorme y ancha escalinata ${ }^{9}$ central que crea una visión ascendente y rígida. El TS tiene 3 estancias paralelas cubiertas con bóveda maya y está rematado con una pesada y maciza crestería. El T2, enfrentado al T1, es un TM de 4 cuerpos superpuestos (Lámina 5c). Se trata de una pirámide más ancha y baja que se ve alterada por los diferentes tamaños de la escalinata central y la crestería del TS, que está decorada con máscaras (AAVV; 2002: 74-101 y 200-211; Longhena, 2005: 242-251; Marquina, 1981: 551-557; Sondereguer, 1989: 36-38 y Sondereguer, 2006: 33-34).

Entre los dos templos está la GP, donde se realizaban los rituales y ceremonias más importantes. En ella se

7 En el CA de Tikal hay otros templos importantes, como el Templo 3 (T3) o del Sacerdote Jaguar, el Templo 4 (T4) o el Templo 5 (T5), todos de diferentes tamaños y alturas. En ellos las esculturas y los relieves de las jambas, dinteles y muros muestran a gobernantes de las diferentes dinastías mayas y a dioses de su panteón.

$8 \mathrm{Al}$ tener 9 niveles este TM está relacionado con el Inframundo. Además, en su interior alberga la tumba de diferentes gobernantes mayas de Tikal, lo cual reafirma la posibilidad de que se creen vínculos con el más allá, los ancestros y los muertos.

9 Las dimensiones y amplitudes de está pirámide remarcan la importancia del edificio, así como de los rituales que se llevaban a cabo en ella y el pueblo podía ver perfectamente desde la Gran Plaza situada delante, o bien, desde el Templo 2. 


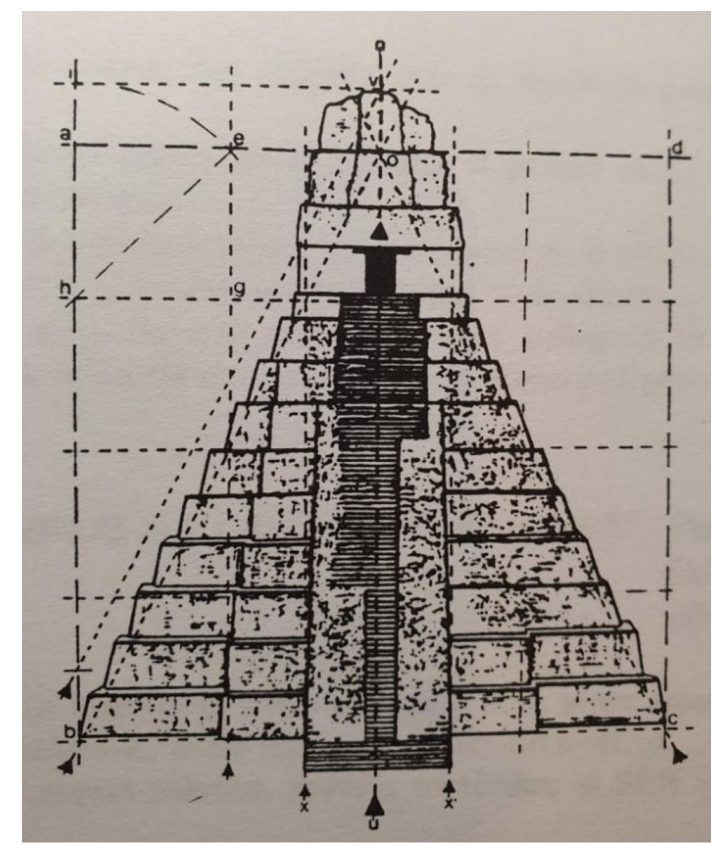

Lámina 5c. Alzado Templo 1 de Tikal - Sondereguer, C.; 1989

encuentran la mayoría de estelas importantes, aunque están repartidas por todo el CA. Éstas se usaban como marcadores de los rituales y como objetos conmemorativos de la vida de los diferentes gobernantes. Están decoradas ricamente con figuras antropomorfas muy detallistas, con ricos tocados y atributos de poder; acompañados por animales, jeroglíficos, dioses y antepasados (Alcina, 1991: 5253; Piña y Matos, 1998: 141-225 y Stierlin, 2001: 35-56).

Lo que destaca realmente de Tikal es la magnífica visualización que se tiene de todo el CeC desde los TS de los TM y la integración de los edificios, cubiertos en su origen de colores vivos y brillantes (hoy perdidos en su mayoría) y decorados con hermosas esculturas, dentro del entorno salvaje, creando así una gran ciudad de coloren medio de la selva tropical (Barbier, 1997; Domenici, 2007: 76-114; Piña y Matos, 1998: 141-225; Stierlin, 1997: 104-167; Stierlin, 2001; Uriarte, 2012: 122-137 y Vidal, 1999b: 65-70).

\section{Mesoamérica: Palenque}

El CA de Palenque tuvo su época de mayor esplendor bajo el reinado de Pacal el Grande (615-683) y su hijo, los cuales hicieron remodelaciones en los edificios más importantes, la escultura cobra más fuerza y protagonismo y la construcción de la famosa tumba de Pacal en el Templo

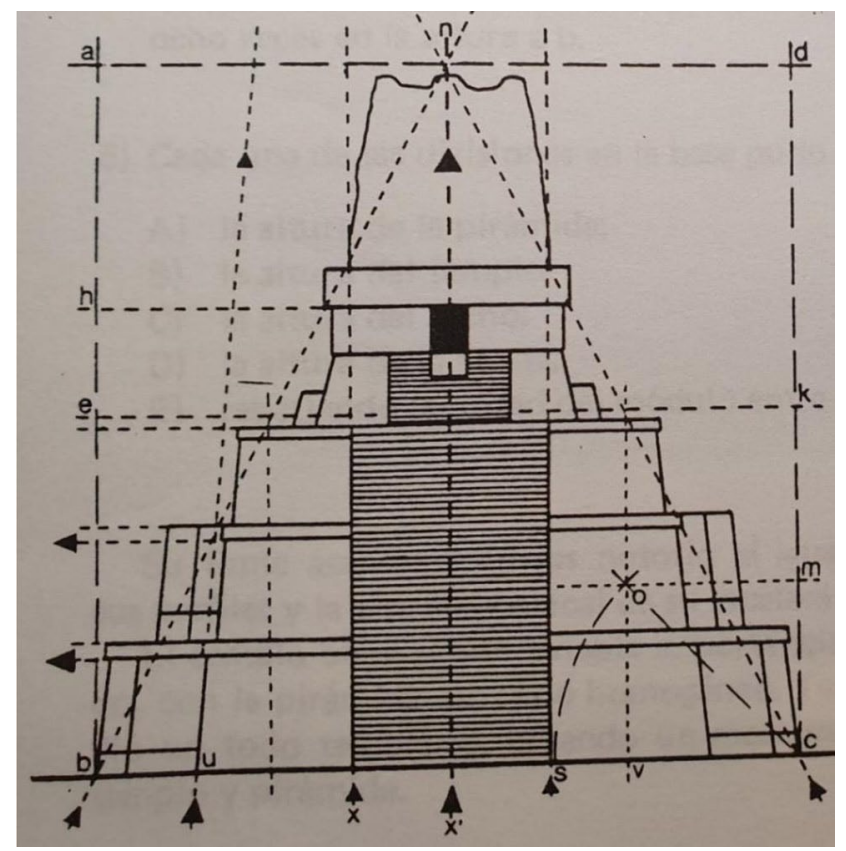

Lámina 5d. Alzado Templo 2 de Tikal - Sondereguer, C.; 1989

de las Inscripciones (TIn), que marcó un antes y un después. Aquí los TM se convierten en la residencia de los dioses y los gobernantes. El CoC está repleto de terrazas artificiales y túneles porque lo rodean ríos y montañas. Se han encontrado muchas zonas con entierros con ajuares muy ricos (gobernantes y élite) y sacrificios humanos que remarcan los linajes y los periodos de poder de cada dinastía (Aimi, 2003: 84-85; Alcina, 1991: 50-51; Barbier, 1997; Campagno, 2007: 39-66; Carceller, 2010: 58-61; De la Garza, 1998: 101-139; Domenici, 2007: 58-61; Longhena, 2005: 218-231; López Austin y López Lujan, 1996; Muñoz, 1999a: 25-30; Muñoz, 1999b: 43-50; Sondereguer, 1998: 42-43; Sondereguer, 2006: 35-38 y 61-67; Stierlin, 1997: 104-167; Vidal, 1999a: 19-24 y Vidal, 2002).

El CA está organizado urbanísticamente, pese a todas las remodelaciones y ampliaciones, y está orientado siguiendo el recorrido del sol para favorecer las observaciones astronómicas. El calendario, los mitos y el culto a los dioses se ven reflejados, tanto en las formas arquitectónicas, como en la decoración (Carceller, 2010: 58-61; De la Garza, 1998: 101-139; Sondereguer, 1998: $42-43$ y Stierlin, 1997: 104-167).

La arquitectura es armónica y simétrica, con los basamentos monumentales y sencillos. Los TM son más anchos y pesados, con escalinatas grandes decoradas con alfardas y los TS son más amplios, con más crujías 
y bóvedas falsas y de aristas paralelas, haciendo que los interiores sean diáfanos con los muros delgados. Las cresterías son caladas y están ricamente decoradas (AAVV; 2002: 60-73; Alcina, 1991: 50-51; Barbier, 1997; Carceller, 2010: 58-61; De la Garza, 1998: 101-139; Domenici,2007: 104-109 y 114-115; Longhena, 2005: 218-231; López Austiny López Lujan, 1996; Marquina, 1981: 603653; Muñoz, 1999a: 25-30; Muñoz, 1999b: 43-50; Piñay Matos,1998: 141-225; Quintana, 1999: 77-82; Ruz, 1992; Sondereguer, 1989: 38-39; Sondereguer, 1998: 42-43; Sondereguer,2006: 35-38; Stierlin, 1997: 104-167; Stierlin, 2001: 67-89; Uriarte, 2012: 116-119 y Vidal, 2002).

«Este ornamento transforma una pared en escultura y borra la frontera entre arquitectura y decoración».

(Stierlin, H.; 2001: 31)

La arquitectura está decorada con magníficos relieves y esculturas de una perfección técnica y estética increíble
(Lámina 6a). No hay un lugar que no esté ornamentado: muros, dinteles, cornisas, jambas, frisos, vanos, ventanas, taludes, alfardas... Las figuras son expresivas, proporcionadas, naturalistas y sensuales. La arquitecturaescultórica se fusiona de tal modo con la naturaleza que se integra en el paisaje como si fuese uno, creando así un entorno sagrado con magníficas vistas. Normalmente se representa a los gobernantes y suelen ir acompañados por jeroglíficos con su nombre y títulos y algunos dioses (Alcina, 1991: 50-51; Barbier, 1997; Longhena, 2005: 218-231; Piña y Matos, 1998: 141-225; Ruz, 1992; Sondereguer, 1989: 38-39; Sondereguer, 1998: 42-43; Sondereguer, 2006: 35-38 y Uriarte, 2012: 119-122).

Uno de los monumentos más destacados es el TIn (Láminas 6b y 6c). Es la PE más grande y horizontal de todo el CeC, un TM compuesto de 9 cuerpos superpuestos $(8+1)$ que alberga la tumba de Pacal. La escalinata central tiene alfardas y relieves del gobernante y diferentes dioses, y la escalera interior de acceso a la tumba tiene relieves de los antepasados de Pacal. En la tumba

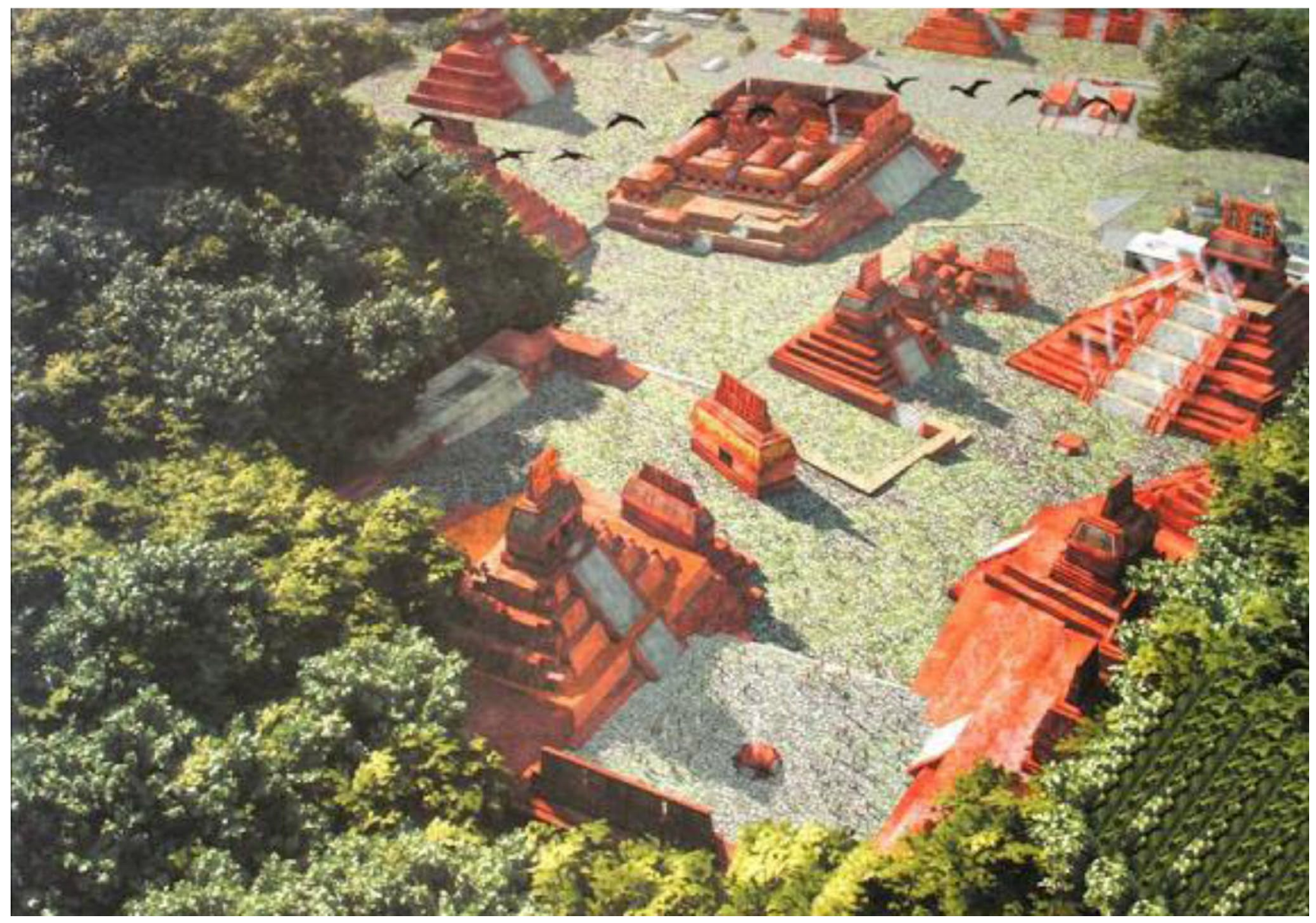

Lámina 6a. Reconstrucción del centro ceremonial de Palenque 


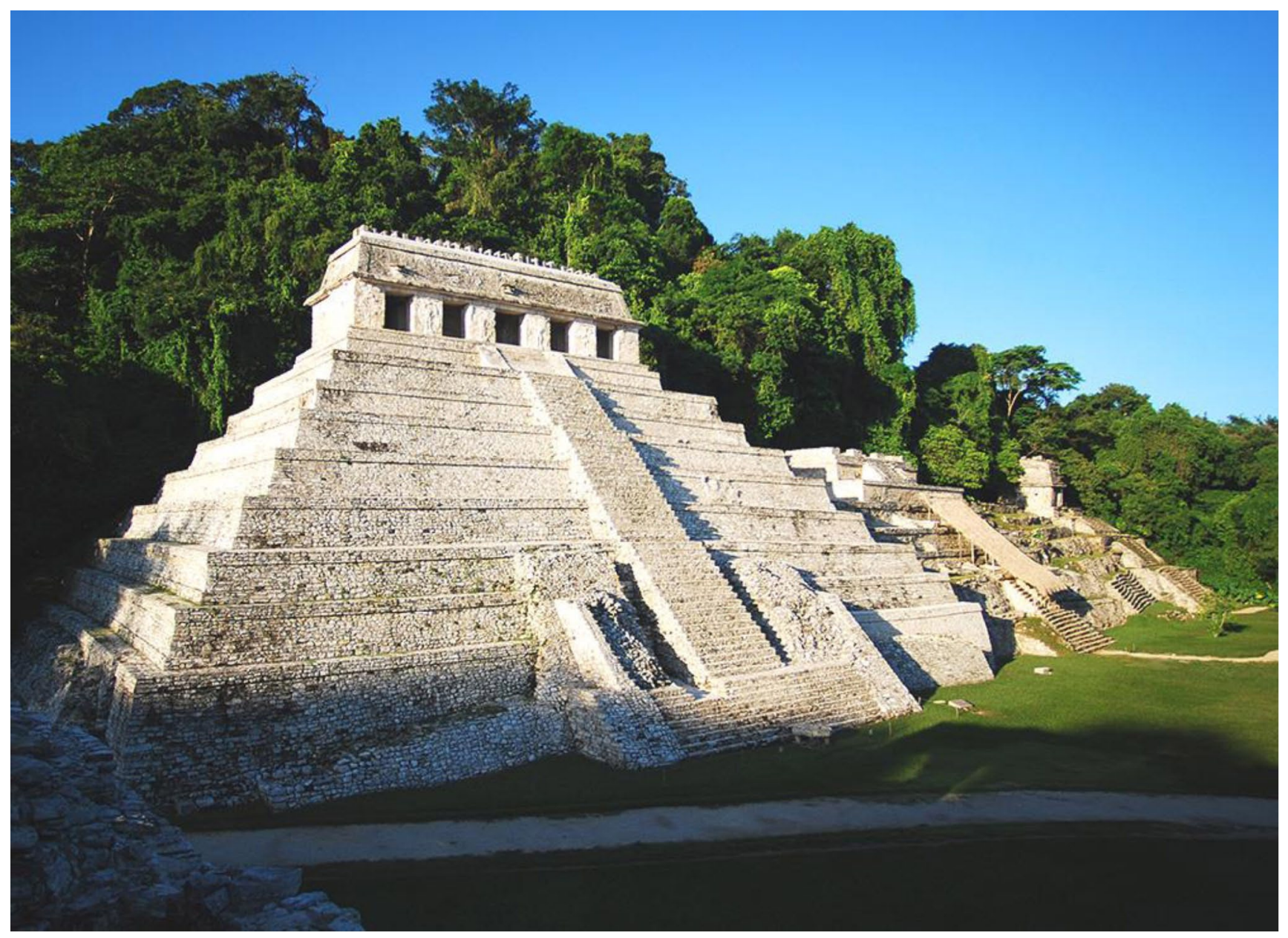

Lámina 6b. Vista actual del templo de las Inscripciones de Palenque
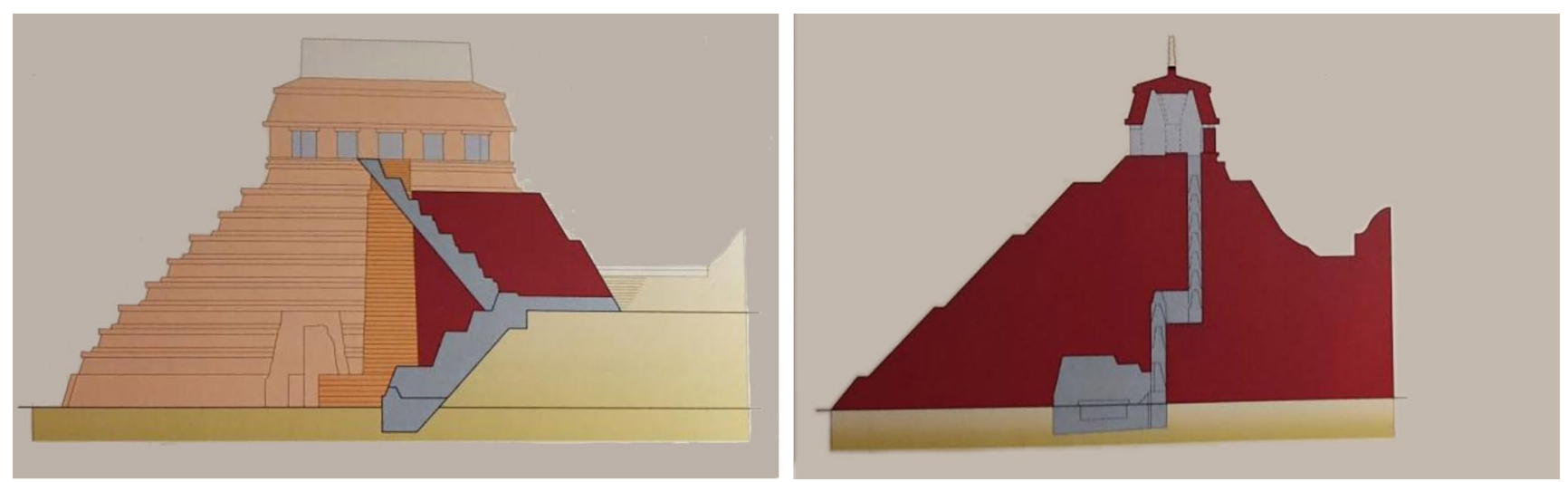

Lámina 6c. Alzado del templo de las Inscripciones de Palenque - x - Stierlin, H.; 2001 


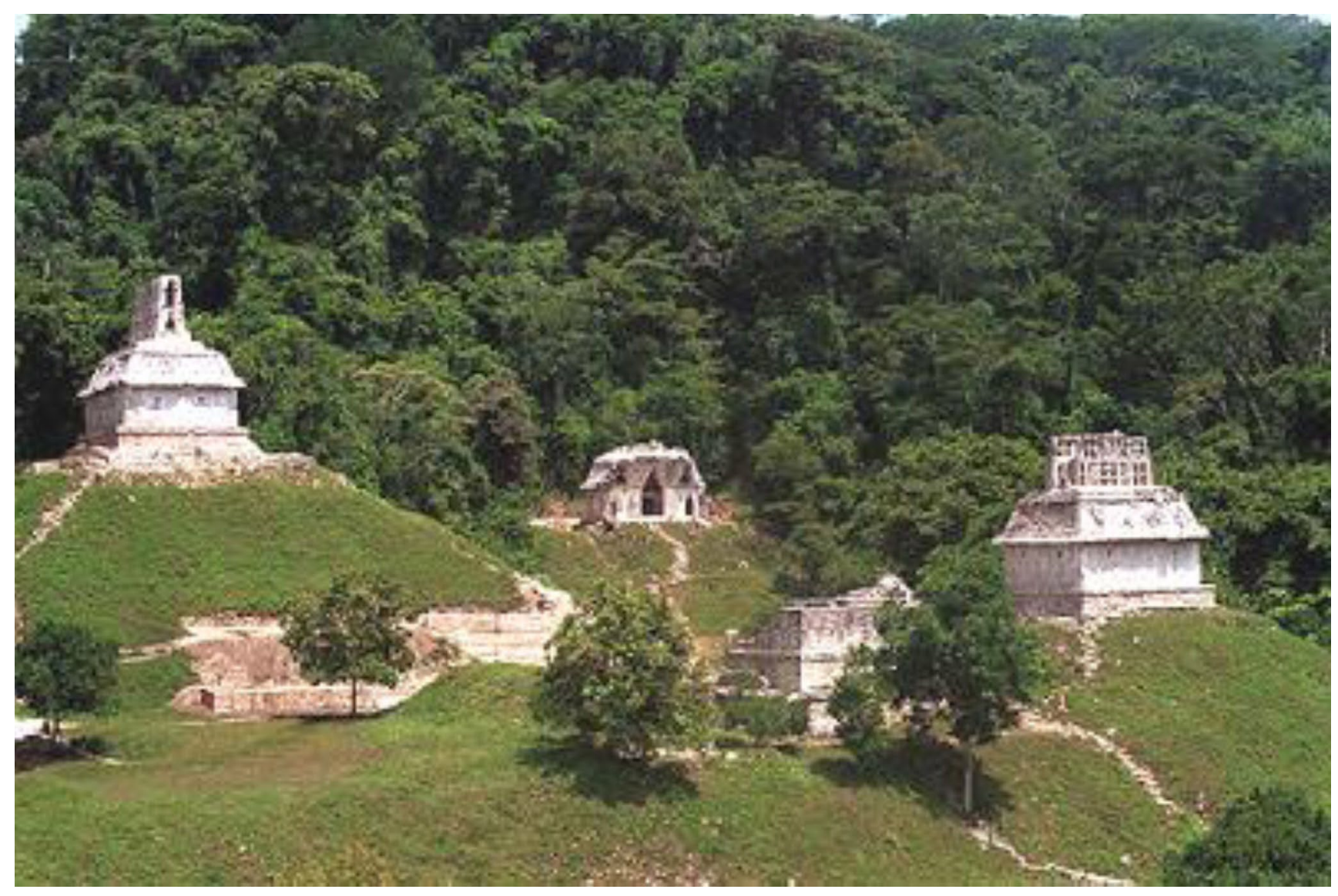

Lámina 6d. Conjunto de las Cruces

se encuentran ofrendas, sacrificios y un gran sarcófago con relieves y una rica máscara mortuoria. El TS es amplio, con 2 crujías y 5 vanos (en lugar de 3 o 1) decorado con 3 paneles con glifos y figuras que narran el recorrido que debe hacer Pacal en el más allá al morir. Para poder entender este edificio debemos comprender los relieves que lo decoran, pintados originalmente, la disposición de cada elemento y su forma arquitectónica en relación a su concepción del Universo (Carceller, 2010: 58-61; De la Garza, 1998: 101-139; Domenici, 2007: 104-109; Longhena, 2005: 218-231; Marquina, 1981: 646-650; Ruz, 1992; Sondereguer, 1989: 38-39; Sondereguer, 2006: 35-38 y Stierlin, 2001: 77-79).

El otro grupo arquitectónico destacado es el Complejo de las Cruces (Lámina 6d), compuesto por el Templo del Sol (TSo), el Templo de la Cruz (TC) y el Templo de laCruz Foliada (TCF). Son 3 TM construidos sobre una plataforma rectangular orientada al sol según los equinoccios. En ellas hay diferentes relieves y esculturas que muestran el culto al maíz, al sol y la fertilidad, por lo tanto, son símbolo de vida y regeneración. El TSo está al
$\mathrm{N}$ y consta de 4 plataformas superpuestas con tablero. Los muros son delgados y los interiores amplios. Todo está decorado con figuras de guerreros con escudos y lanzas, relacionados con los mitos y el poder de los gobernantes. El contraste de la barroca decoración con la arquitectura y el paisaje crea enormes claroscuros. El TC está al S y tiene 13 escalones y está decorado con relieves de Pacal junto a su hijo, para demostrar su origen divino y asegurar su ascensión al cielo. El TCF se encuentra al Oy sus relieves representan al dios del maíz mostrando así su función ritualística para propiciar la fertilidad y el cultivo (Carceller, 2010: 58-61; De la Garza, 1998: 101139; Longhena, 2005: 218-231; Marquina, 1981: 641646; Sondereguer, 2006: 35-38 y Stierlin, 2001: 84-85).

Lo más característico del CeC de Palenque es la integración de los edificios en la naturaleza a través de la decoración y la disposición de los edificios. Además, el uso de los jeroglíficos y las esculturas con las figuras de los gobernantes aportan muchos datos importantes de la historia de la ciudad y las dinastías. Palenque es una ciudad fascinante llena de esculturas con colores brillantes 
(muchas con resto de pigmentación) creada por los gobernantes para los dioses, pero también para reafirmar y reforzar su linaje (Barbier, 1997; De la Garza, 1998: 101-139; Domenici, 2007: 104-115; López Austin y López Lujan,1996; Piña y Matos, 1998: 141-225; Ruz, 1992; Sondereguer, 1998: 42-43; Stierlin, 1997: 104-167; Stierlin, 2001: 67-89; Uriarte, 2012: 122-137; Vidal, 1999b: 65-70 y Vidal, 2002).

\section{Reflexiones finales}

Todos los TM siguen los mismos patrones arquitectónicos e integran la escultura y la pintura en ella para dotarla de un fuerte simbolismo religioso y, en ocasiones, político. El pensamiento cosmológico de estas civilizaciones precolombinas es similar, todas son culturas de origen mítico donde la MS, la fertilidad y los ciclos naturales en relación con el calendario son los puntos principales de su cosmovisión y, la mejor manera de plasmar esta idea arquitectónicamente es a través de la PE-TM, entendida esta como la escalera de ascensión al
Cielo o de descenso al Inframundo. Además, los relieves y esculturas policromadas están integrados de tal forma en la arquitectura que crean una visión plástica y poética inigualable. Son imágenes con un enorme simbolismo religioso que muestran algunos de los dioses principales de su panteón y, en algunos casos, la figura del gobernante divinizado, que está ligada a la propaganda política que se hace del mismo soberano para reafirmar su poder y su origen divino. Así pues, tanto la forma arquitectónica como la decoración escultórica y pictórica de estos $\mathrm{CeC}$, albergan un sentido religioso, mítico y político (Láminas 7a, 7b, 7c y 7d).

En estas sociedades amerindias el hombre reacciona del mismo modo, pese a estar en diferentes lugares y tener recursos muy dispares. Son civilizaciones de origen y discurso mítico con una fuerte religiosidad, que se basan en sus creencias cosmológicas y religiosas, en sus antepasados, en la relación y comprensión que ellos tienen con los dioses y la integración de la arquitectura en la naturaleza para crear, mediante el TM, la imagen sagrada de la MP. Esta representación arquitectónica de lo

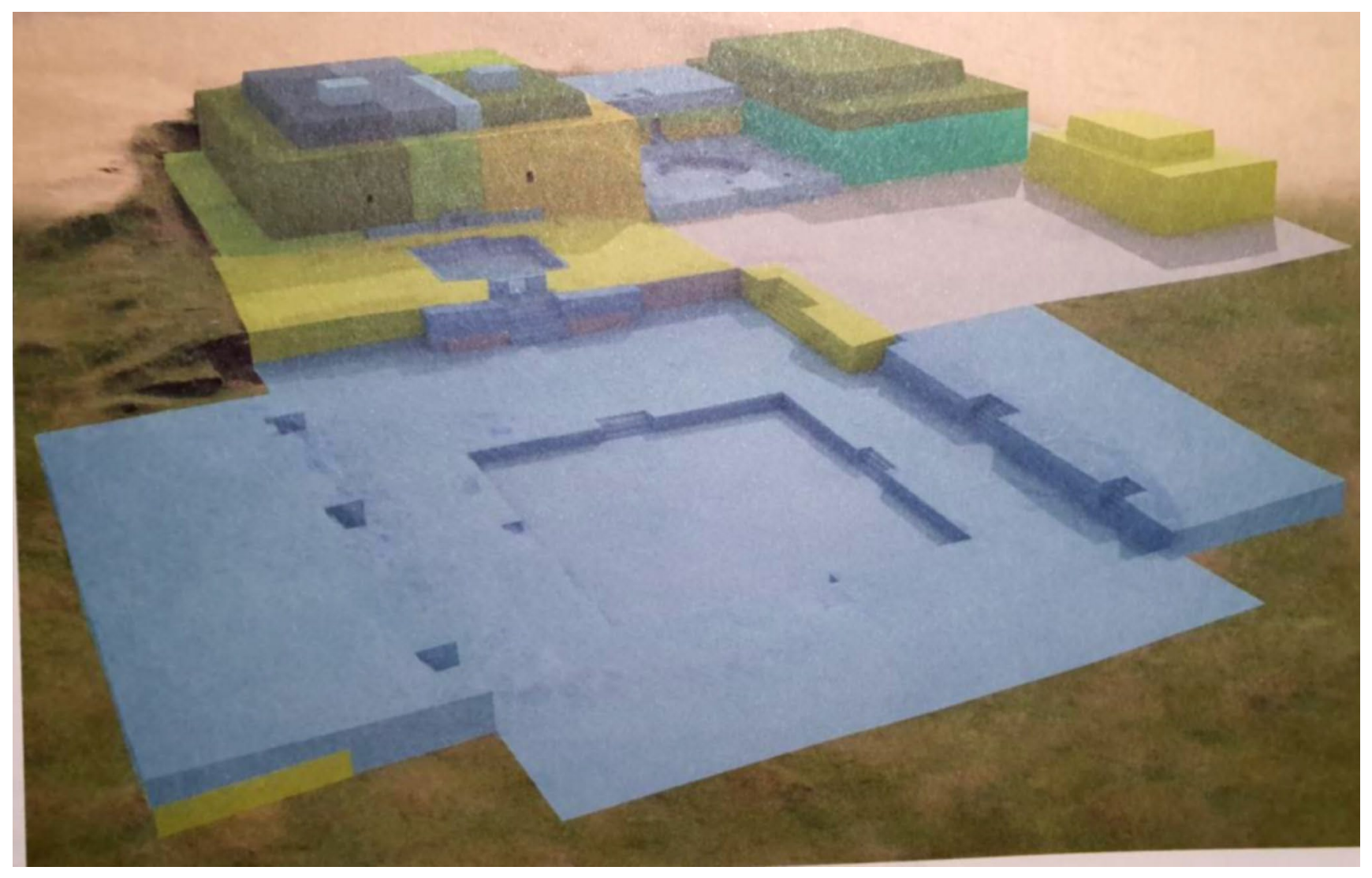

Lámina 7a. Reconstrucción isométrica del centro ceremonial de Chavín 


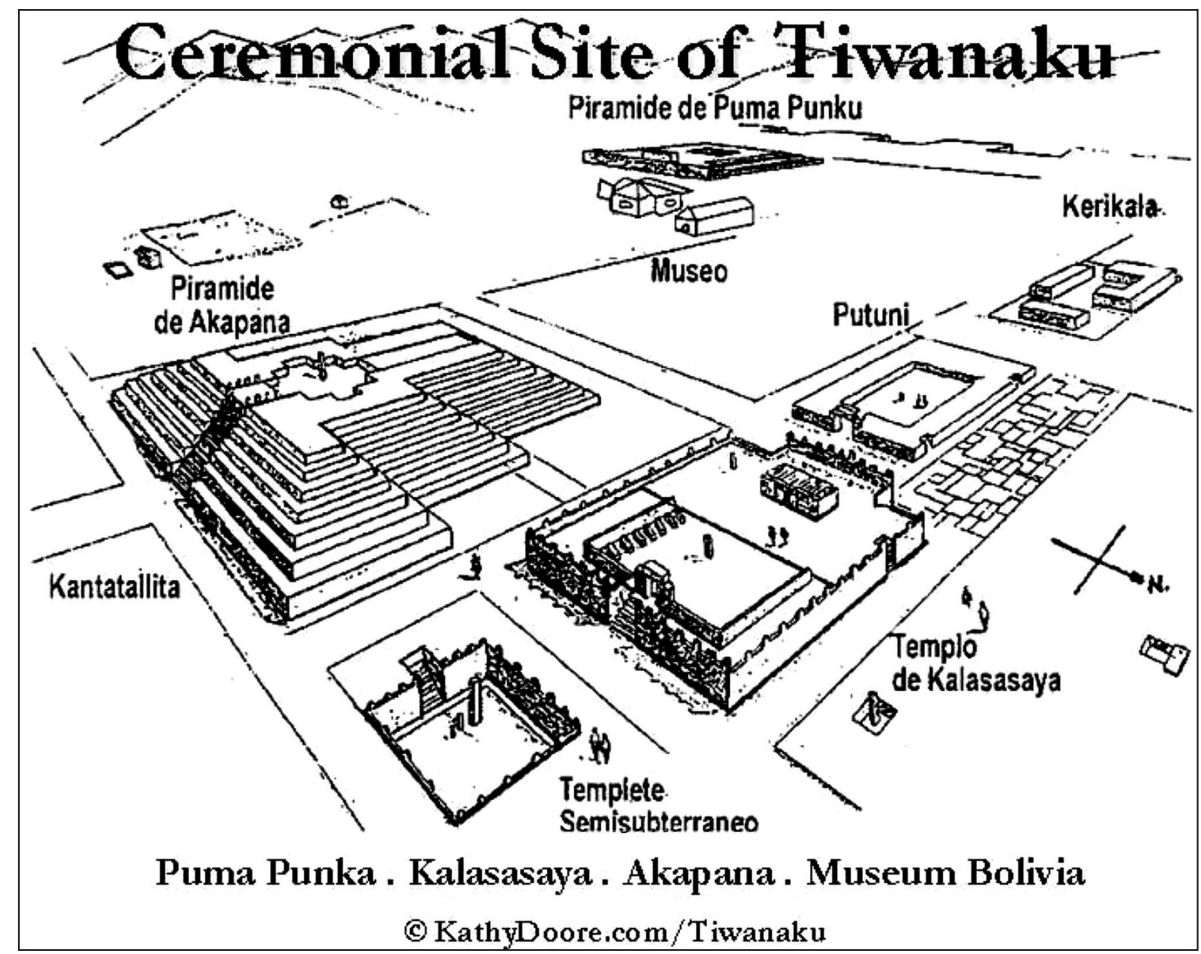

Lámina 7b. Reconstrucción del centro ceremonial del sitio de Tiahuanaco

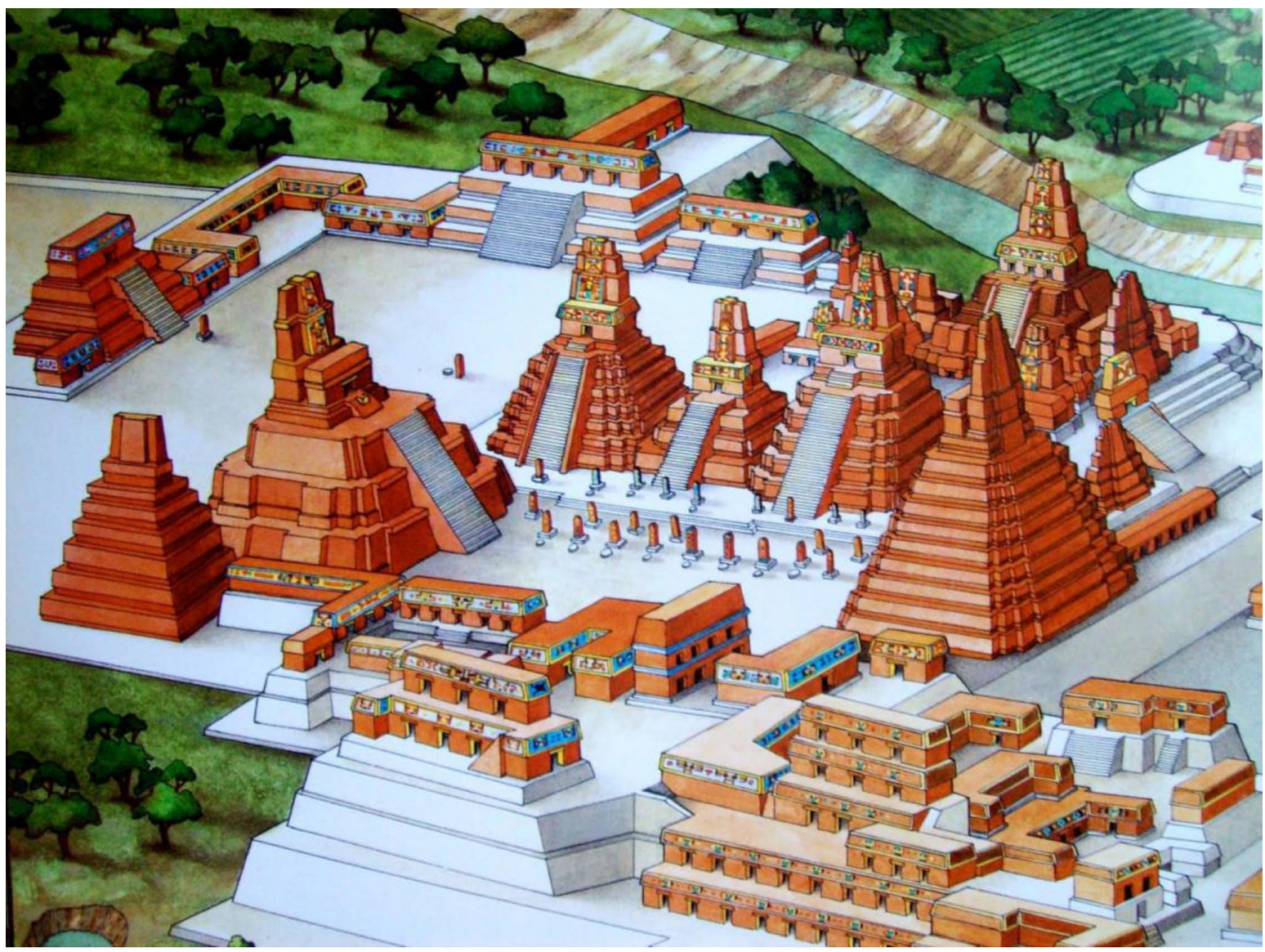

Lámina 7c. Reconstrucción del centro ceremonial de Tikal. La ciudad roja 


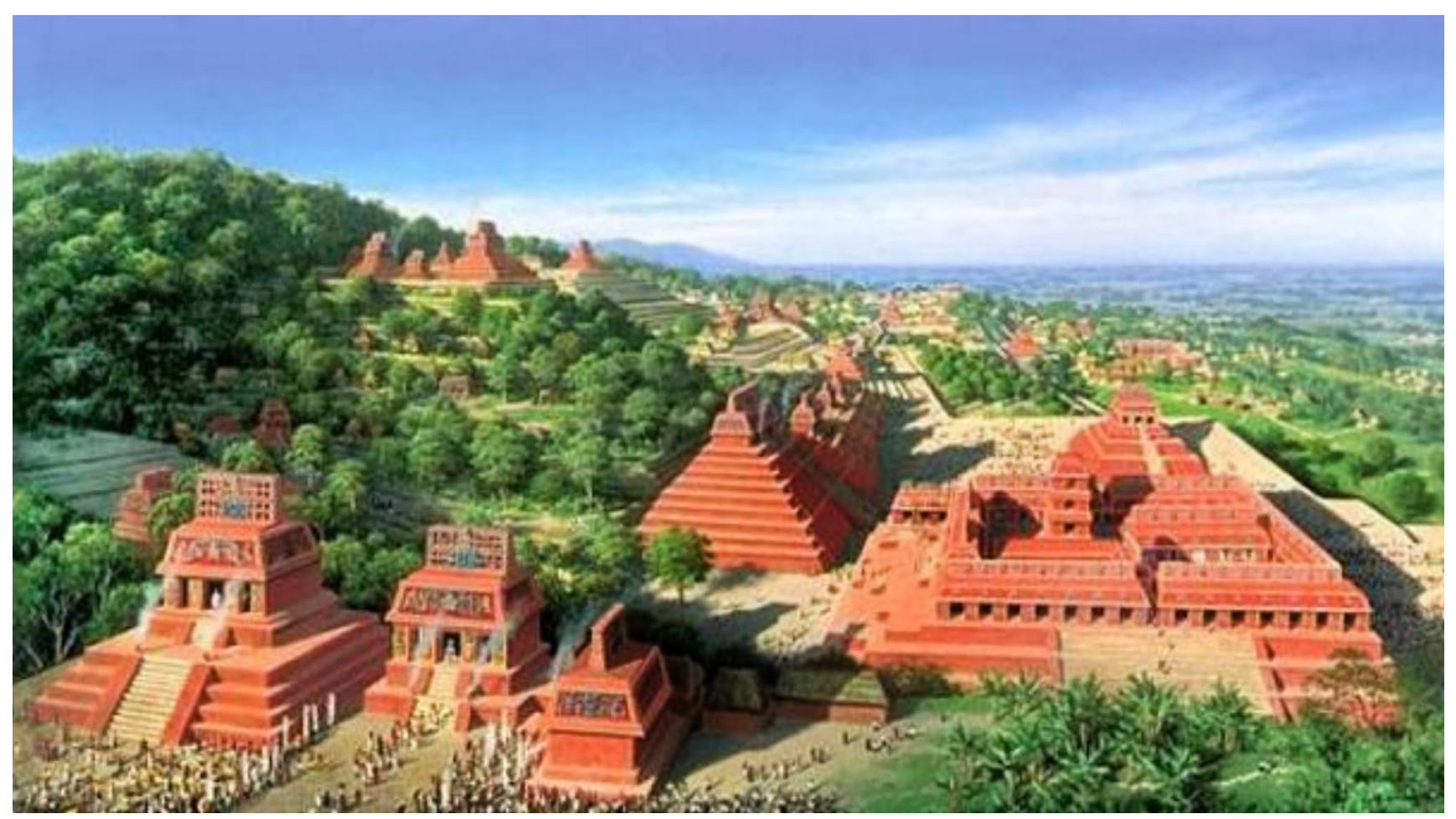

Lámina 7d. Palenque: Reconstrucción del complejo ceremonial de Palenque

sagrado les permite comunicarse con los dioses y los seres sobrenaturales a través de rituales celebrados en las grandes plazas y PE, donde la arquitectura-escultórica y el color juegan un papel fundamental para entender, no solo el cómo, sino el por qué y para qué se realizaban estos TM y cómo se utilizaban en su origen.

Pese a que existen varias reconstrucciones hipotéticas de algunos $\mathrm{CoC}$ mesoamericanos, aún queda mucho trabajo por hacer en la zona andina. Es cierto que muchos de los estudios mencionan la existencia de relieves y pinturas en los templos y plazas, pero no acostumbran a dar detalles en cuanto a formas, disposición ni composición. La mayoría se limitan al análisis de las esculturas exentas y los relieves mejor conservados de determinadas zonas de los complejos y, al contrario que en Mesoamérica, no hay ninguna reconstrucción del aspecto arquitecto-escultórico-pictórico que debían tener estos TM ni los CeC en su época de mayor esplendor. Esto hace que la interpretación y la lectura de estos monumentos sea aún más difícil e inexacta. Pese a ello, podemos establecer nexos de unión y ver similitudes entre estos TM de culturas distintas, de zonas geográficas muy alejadas y periodos diferentes, porque se basan en principios morales y creencias análogas. Los TM se utilizaban como telón de fondo para llevar a cabo los ritos más significativos dentro del CA, es decir, los TM eran los espacios sagrados donde se teatralizaban las ceremonias más importantes, el lugar donde se veían, interactuaban y admiraban los rituales. Por ello, hay que tener en cuenta todos los elementos que hay dentro del $\mathrm{CoC}$ para poder entender, no solo el cómo, sino el por qué y para qué se realizaban estos centros.

\section{Bibliografía general $^{10}$}

AIMI, A.; 2003. Mesoamérica. Olmecas, mayas, azteca: las grandes civilizaciones del Nuevo Mundo. Art Book, Electa, Mateu Cromo Arte Gráficas, S.A., Madrid.

ALCINA FRANCH, J.; 1991. El Arte Precolombino. Biblioteca Básica de Arte, Grupo Anaya, S.A., Madrid.

BARBIER, J. P.; 1997. Guía d'Art Precolombí, Musée Barbier Mueller. Skira Editore, Milán.

CAMPAGNO, M.; 2007. El origen de los primeros Estados. La "revolución urbana" en América precolombina. Universidad de Buenos Aires, Eudeba, Buenos Aires.

10 Por temas de extensión, en este apartado solo se han citado una selección de todas las fuentes bibliográficas consultadas para realizar el presente artículo. En la apéndice hay toda la bibliografía. 
DE LA FUENTE, B.; STAINES CICERO, L. y ARELLANO HERNÁNDEZ, A.; 1998. El arte. Centinelas de la eternidad. En Piña Chan, R. y Matos Moctezuma, E.; Los mayas del período clásico, Corpus Precolombino. Sección Las Civilizaciones Mesoamericanas, pp. 141-226. Instituto Nacional de Antropología e Historia, Lunwerg Editores S.A., Barcelona.

LAVALLÉE, D.; 1997. Arts de l'antic Perú, en Arts Rituals del Nou Continent. Amèrica Precolombina, pp. 168-204. Musée Barbier Mueller, Skira Editore, Barcelona.

vLONGHENA, M.; 2005. México Antiguo. Ediciones Folio, S.A., Barcelona.

LÓPEZ AUSTIN, A.; 1993. La cosmovisión mesoamericana. Apuntes manuscritos cedidos por el autor, Universidad Autónoma de Barcelona, Facultad de Filosofía y Letras, Cerdanyola del Vallés.

LÓPEZ AUSTIN, A.; 1994. Tamoanchan y Tlalocan. Fondo de Cultura Económica, México.

LÓPEZ AUSTIN, A. y LÓPEZ LUJAN, L.; 1996. El pasado indígena. Fideicomiso Historia de las Américas: Serie hacía una nueva historia de México, Fondo de Cultura Económica, México.

MARQUINA, I.; 1981. Arquitectura prehispánica. Tomo II, Instituto Nacional de Antropología e Historia, México.

QUINTANA SAMAYOA, Ó.; 1999. El uso de los sitios arqueológicos y su incorporación a la vida contemporánea. En MUÑOZ COSME, G.; VIDAL LORENZO, C. y VALDÉS GÓMEZ, J. A. (coms.); Los Mayas. Ciudades Milenarias de Guatemala, pp. 77-82. Ministerio de Educación y Cultura de España, Ayuntamiento de Zaragoza, Generalitat Valenciana, IberCaja, talleres gráficos Edelvives, Zaragoza.

SONDEREGUER, C.; 1998. Arquitectura precolombina. Catálogo de tipos de urbanismos, de obras y constructivos. Norte, Meso, Centro y Suramérica. Ediciones Corregidor, Buenos Aires.

STIERLIN, H.; 1997. L'Art de Mesoamèrica. En Arts Rituals del Nou Continent. Amèrica Precolombina, pp. 104-167. Musée Barbier Mueller, Skira Editore, Barcelona.

URIARTE, M. T.; 2012. Arte y arqueología en el altiplano central de México. Una visión a través del arte. Universidad Nacional Autónoma de México, Dirección General de Publicaciones y Fomento Editorial, Instituto de Investigaciones Estéticas, Siglo XXI Editores, México.

VIDAL, J. A. (ed.); 2002. El Mundo Precolombino. MMII Editorial Océano, Barcelona.

\section{Bibliografía específica}

AAVV; 2002. Espacios Sagrados. Arquitectura maya en la obra de Teoberto Maler. Universitat de València, Selvi Artes Gráficas, València.

BENÍTEZ, L.; 2009. Descendants of the Sun: Calendars, Myth and the Tiwanaku State. En YOUNG-SÁNCHEZ, M. (ed.); Tiwanaku: papers from the 2005 Mayer Center Symposium at the Denver Art Museum, pp. 49-82.Denver Art Museum, Denver.

BERENGUER RODRÍGUEZ, J.; 2000. Tiwanaku. Señores del Lago Sagrado. Museo Chileno de Arte Precolombino, Morgan Impresores, Santiago de Chile.

BISCHOF, H.; 2012. Die Kunst von Chavín - Ursprünge und Entwicklung. En FUX, P. (ed.); Chavín. Perus geheimnisvoller Anden-Tempel, pp. 134-157. Museum Rietberg Zürich un Verlag Scheidegger \& Spiess AG, Zürich.

BRUGHETTI, R.; 2000. Tiwanaku: etapas de su arte. En BLANCO, R. (ed.); Arte Prehispánico: creación, desarrollo y presencia. Temas de la Academia, pp. 7-14. Academia Nacional de Bellas Artes, Mercantil S.A., Argentina, año 2, no 2 .

CARCELLER SINDREU, M.; 2010. El simbolismo de la montaña en la antigüedad. Estudio iconográfico de lo montañoso en las culturas de pensamiento mítico. Tesina codirigida por los Drs. Victòria Solanilla y Josep Cervelló, IEOPA-UAB, Barcelona.

CARLSON, U.; 2012a. Chavín enigmático. Simbolismo y su significación. Una contribución a la interpretación de la iconografía de Chavín. Iconografía Andina, Braunschweig, pp. 3-28.

CARLSON, U.; 2012b.Inadequate interpretations of the divine image of Chavín. Inaccurate interpretations of the divine image of Chavín. Andean Iconography, Braunschweig, pp. 19-30.

CARLSON, U.; 2013.The symbolism of reliefs and Wall paintings of ancient central and northern Peruvian coastal sites.A contribution to the understanding of the symbolism of ancient Peruvian art.Andean Iconography, Braunschweig, pp. 2-18.

CLADOS, C.; 2009.New Perspective on Tiwanaku Iconography. En YOUNG-SÁNCHEZ, M. (ed.); Tiwanaku: papers from the 2005 Mayer Center Symposium at the Denver Art Museum, pp. 101-114.Denver Art Museum, Denver.

CONKLIN, W. J.; 2009.The Iconic Dimension in Tiwanaku Art. En YOUNG-SÁNCHEZ, M. (ed.); Tiwanaku: papers from the 2005 Mayer Center Symposium at the Denver Art Museum, pp. 115-132.Denver Art Museum, Denver.

DE LA GARZA, M.; 1998. Las fuerzas sagradas del Universo Maya. En PIÑA CHAN, R. y MATOS MOCTEZUMA, E.; Los mayas del período clásico, Corpus Precolombino. Sección Las Civilizaciones Mesoamericanas, pp. 101-140. Instituto Nacional de Antropología e Historia, Lunwerg Editores S.A., Barcelona.

DOMENICI, D.; 2007. Mayas: los tesoros de las antiguas civilizaciones. RBA Libros, S.A., Barcelona.

FUX, P.; 2012. Was ist Chavín? En FUX, P. (ed.); Chavín. Perus geheimnisvoller Anden-Tempel, pp. 21-24. Museum Rietberg Zürich un Verlag Scheidegger \& Spiess AG, Zürich.

GUSSINYER I ALFONSO, J.; 1992-93. Notas para el concepto de espacio en la arquitectura precolombina de Mesoamérica. Boletín Americanista, pp. 183-230, Universidad de 
Barcelona, Facultad de Geografía e Historia, Sección de Historia de América, año XXXIII, Barcelona.

GUTIÉRREZ USILLOS, A.; 2003. El dios de las tormentas y divinidades de la lluvia: iconografía del felino de los Andes Septentrionales. Anales del Museo de América, pp. 103118, Madrid.

HOOPES, J. W.; 2009. From Tiwanaku to Machu Picchu: Ushnus and the Architecture of Creation. En YOUNG-SÁNCHEZ, M. (ed.); Tiwanaku: papers from the 2005 Mayer Center Symposium at the Denver Art Museum, pp. 247-272. Denver Art Museum, Denver.

JANUSEK, J. W.; 2005. Patios hundidos, encuentros rituales y el auge de Tiwanaku como centro religioso panregional. Boletín de Arqueología PUCP, no 9, pp. 161-184.

JANUSEK, J. W.; 2010. El surgimiento del urbanismo en Tiwanaku y del poder político en el altiplano andino. En MAKOWSKI HANULA, K. (comp.); Señores de los Imperios del Sol, pp. 1-19. Colección Arte y tesoros del Perú, Lima.

KOLATA, A.; 2004. TheFlow of CosmicPower: Religion, Ritual and ThePeople of Tiwanaku. En LEVINSON, L. y MELUN, A. (eds.); Tiwanaku: ancestors of the Inca, pp. 96-125. Denver Art Museum, University of Nebraska Press, CS Graphics, Singapore.

LUMBRERAS, L. G.; 1993. Chavín de Huántar. Excavaciones en la Galería de las Ofrendas. VerlagPhilipp von Zabern, Mainz.

LUMBRERAS, L. G.; 2012. Religiöse Rite in Chavín un ihre überregionale Bedeutung. En FUX, P. (ed.); Chavín. Perus geheimnisvoller Anden-Tempel, pp. 184-196. Museum Rietberg Zürich un Verlag Scheidegger \& Spiess AG, Zürich.

MAKOWSKI HANULA, K.; 2009.Royal Statues, Staff Gods and the Religious Ideology of the Prehistoric State of Tiwanaku. En YOUNG-SÁNCHEZ, M. (ed.); Tiwanaku: papers from the 2005 Mayer Center Symposium at the Denver Art Museum, pp. 133-164.Denver Art Museum, Denver.

MAKOWSKI HANULA, K.; 2010. Vestido, arquitectura y mecanismo del poder en el Horizonte Medio. En MAKOWSKI HANULA, K. (comp.); Señores de los Imperios del Sol, pp. 1-17. Colección Arte y tesoros del Perú, Lima.

MANZANILLA, L.; 1992. Akapana. Una pirámide en el centro del mundo. Ed. Instituto Investigaciones Antropológicas, México.

MESÍA MONTENEGRO, C.; 2012. Die Entdeckung des Tempels und frühe Deutungsversuche. En FUX, P. (ed.); Chavín. Perus geheimnisvoller Anden-Tempel, pp. 126-133. Museum Rietberg Zürich un Verlag Scheidegger \& Spiess AG, Zürich.

MUÑOZ COSME, G.; 1999a. Las ciudades y el medio natural. En MUÑOZ COSME, G.; VIDAL LORENZO, C. y VALDÉS GÓMEZ, J. A. (coms.); Los Mayas. Ciudades Milenarias de Guatemala, pp. 25-30. Ministerio de Educación y Cultura de España, Ayuntamiento de Zaragoza, Generalitat Valenciana, IberCaja, talleres gráficos Edelvives, Zaragoza.
MUÑOZ COSME, G.; 1999b. La arquitectura maya. En MUÑOZ COSME, G.; VIDAL LORENZO, C. y VALDÉS GÓMEZ, J. A. (coms.); Los Mayas. Ciudades Milenarias de Guatemala, pp. 43-50. Ministerio de Educación y Cultura de España, Ayuntamiento de Zaragoza, Generalitat Valenciana, IberCaja, talleres gráficos Edelvives, Zaragoza.

OLMEDO VERA, B.; 1998. Los mayas del Clásico. En PIÑA CHAN, R. y MATOS MOCTEZUMA, E.; Los mayas del período clásico, Corpus Precolombino. Sección Las Civilizaciones Mesoamericanas, pp. 9-100. Instituto Nacional de Antropología e Historia, Lunwerg Editores S.A., Barcelona.

PIÑA CHAN, R. y MATOS MOCTEZUMA, E.; 1998.Los mayas del período clásico, Corpus Precolombino. Sección Las Civilizaciones Mesoamericanas, pp. 141-225. Instituto Nacional de Antropología e Historia, Lunwerg Editores S.A., Barcelona.

RICK, J. W.; 2012a. Architektur und Kulträume in Chavín de Huántar. En FUX, P. (ed.); Chavín. Perus geheimnisvoller Anden-Tempel, pp. 158-173. Museum Rietberg Zürich un Verlag Scheidegger \& Spiess AG, Zürich.

RICK, J. W.; 2012b. Religion un Autorität in Chavín de Huántar. En FUX, P. (ed.); Chavín. Perus geheimnisvoller AndenTempel, pp. 174-183. Museum Rietberg Zürich un Verlag Scheidegger \& Spiess AG, Zürich.

RUZ LHUILLIER, A.; 1992 (1972). El templo de las inscripciones de Palenque. Fondo de Cultura Económica, México, 2 2 a ed.

SONDEREGUER, C.; 1989. La pirámide templo en Mesoamérica. Morfoproporcionalidad. Arte al Día, Buenos Aires.

SONDEREGUER, C.; 2006. Pirámides y Templos de Egipto y América. Fundamentos ideológicos, morfoproporcionalidad, crítica estética. Nobuko, Buenos Aires.

STIERLIN, H.; 2001. Los mayas. Palacios y pirámides de la selva virgen. TaschenGmbH, Italia.

VIDAL LORENZO, C.; 1999a. El descubrimiento de las Ciudades Milenarias de Guatemala. En MUÑOZ COSME, G.; VIDAL LORENZO, C. y VALDÉS GÓMEZ, J. A. (coms.); Los Mayas. Ciudades Milenarias de Guatemala, pp. 19-24. Ministerio de Educación y Cultura de España, Ayuntamiento de Zaragoza, Generalitat Valenciana, IberCaja, talleres gráficos Edelvives, Zaragoza.

VIDAL LORENZO, C.; 1999b. La expresión artística maya a través de los objetos ceremoniales. En MUÑOZ COSME, G.; VIDAL LORENZO, C. y VALDÉS GÓMEZ, J. A. (coms.); Los Mayas. Ciudades Milenarias de Guatemala, pp. 65-70. Ministerio de Educación y Cultura de España, Ayuntamiento de Zaragoza, Generalitat Valenciana, IberCaja, talleres gráficos Edelvives, Zaragoza.

VRANICH, A.; 2001. La pirámide de Akapana: reconsiderando el centro monumental de Tiwanaku. Boletín de Arqueología PUPC, número 5, Lima, pp. 295-308.

VRANICH, A.; 2009.The Development of the Ritual Core of Tiwanaku. En YOUNG-SÁNCHEZ, M. (ed.); Tiwanaku: papers from the 2005 Mayer Center Symposium at the Denver Art Museum, pp. 11-34.Denver Art Museum, Denver. 
VRANICH, A.; 2010. Plataformas, plazas y palacios en Tiwanaku, Bolivia (500-1000). En MAKOWSKI HANULA, K. (comp.); Señores de los Imperios del Sol, pp. 1-11. Colección Arte y tesoros del Perú, Lima.

YOUNG-SÁNCHEZ, M.; 2004. The Art of Tiwanaku. En LEVINSON, L. y MELUN, A. (eds.); Tiwanaku: ancestors of the Inca, pp. 24-40. Denver Art Museum, University of Nebraska Press.

ZUIDEMA, R. T.; 2009.Tiwanaku Iconography and the Calendar. En YOUNG-SÁNCHEZ, M. (ed.); Tiwanaku: papers from the 2005 Mayer Center Symposium at the Denver Art Museum, pp. 83-100. Denver Art Museum, Denver.

\section{Apéndice 1: Bibliografías}

\section{Bibliografía general}

AIMI, A.; 2003. Mesoamérica. Olmecas, mayas, azteca: las grandes civilizaciones del Nuevo Mundo. Art Book, Electa, Mateu Cromo Arte Gráficas, S.A., Madrid.

ALCINA FRANCH, J.; 1988. Las claves del Arte Precolombino. Cómo identificarlo. Editorial Ariel, S.A., Barcelona.

ALCINA FRANCH, J.; 1991. El Arte Precolombino. Biblioteca Básica de Arte, Grupo Anaya, S.A., Madrid.

BARBIER, J. P.; 1997. Guía d’Art Precolombí, Musée Barbier Mueller. Skira Editore, Milán.

BARBIER, J. P.; DUBOIS, T. y FASEL, F.; 1991. El Quart Continent. L'art precolombí, Fundació “LaCaixa”, Musée Barbier Muller, Barcelona.

BERNAL Y GARCIA, I. y SIMONI ABBAT, M.; 1986.Le Mexique des origines aux Aztèques. Vol. I, Editorial Gallimard, Paris.

BURENHULT, G. (ed.); 1994. Nuevo Mundo, Nuevos Horizontes. Incas, mayas y aztecas. Editorial Debate, Printer Industria Gráfica, S.L., Madrid.

CAMPAGNO, M.; 2007. El origen de los primeros Estados. La "revolución urbana" en América precolombina. Universidad de Buenos Aires, Eudeba, Buenos Aires.

CIUDAD RUIZ, A.; IGLESIAS PONCE DE LEÓN, Má J. y SERROCHE CUERVA, M.; 2010. El ritual en el mundo maya: de lo privado a lo público. Sociedad Española de Estudios Mayas, Madrid.

COMA-CROS, D. y TELLO, A.; 2005. Historia del Arte: América Precolombina. Arte colonial. Editorial Salvat, S.L., Diario EL PAÍS, S.L., Madrid.

DE LA FUENTE, B.; 2003. El arte, la historia y el hombre. Arte prehispánico de México: estudios y ensayos, obras, Tomo 1, El Colegio Nacional, México.

DE LA FUENTE, B.; STAINES CICERO, L. y ARELLANO HERNÁNDEZ, A.; 1998. El arte. Centinelas de la eternidad. En PIÑA CHAN, R. y MATOS MOCTEZUMA, E.; Los mayas del período clásico, Corpus Precolombino. Sección Las Civilizaciones Mesoamericanas, pp. 141-226. Instituto Nacional de Antropología e Historia, Lunwerg Editores S.A., Barcelona.
FAUGÈRE, B. (coord.); 2007. Dinámicas culturales entre el occidente, el Centro-norte y la Cuenca de México, del Preclásico al Epiclásico. Colegio de Michoacán, Centro de Estudios Mexicanos y Centroamericanos, México.

GREMDROP, P.; 1997. Diccionario de arquitectura mesoamericana. Trillos, México.

LAVALLÉE, D.; 1997. Arts de l'antic Perú, en Arts Rituals del Nou Continent. Amèrica Precolombina, pp. 168-204. Musée Barbier Mueller, Skira Editore, Barcelona.

LONGHENA, M.; 2005. México Antiguo. Ediciones Folio, S.A., Barcelona.

LÓPEZ AUSTIN, A. y LÓPEZ LUJAN, L.; 1996. El pasado indígena. Fideicomiso Historia de las Américas: Serie hacía una nueva historia de México, Fondo de Cultura Económica, México.

LÓPEZ AUSTIN, A.; 1993. La cosmovisión mesoamericana. Apuntes manuscritos cedidos por el autor, Universidad Autónoma de Barcelona, Facultad de Filosofía y Letras, Cerdanyola del Vallés.

LÓPEZ AUSTIN, A.; 1994. Tamoanchan y Tlalocan. Fondo de Cultura Económica, México.

MARQUINA, I.; 1981a. Arquitectura prehispánica. Tomo I, Instituto Nacional de Antropología e Historia, México.

MARQUINA, I.; 1981b. Arquitectura prehispánica. Tomo II, Instituto Nacional de Antropología e Historia, México.

MILLER, M. E.; 1999. Maya Art and Architecture. Thames and Hudson, Nueva York.

MONTEJO, V. y GARAY, L.; 2005 (1999). Popul Vuj. Libro sagrado de los mayas. Artes de México, México, 3a edición.

PATERNOSTO, C.; 2000. La conexión Norte/Sur: una abstracción de América. En BLANCO, R. (ed.); Arte Prehispánico: creación, desarrollo y presencia. Temas de la Academia, pp. 155-166. Academia Nacional de Bellas Artes, Mercantil S.A., Argentina, año 2, no 2.

PAZ, O.; 1997. El arte de México. Materia y sentido», en Arts Rituals del Nou Continent. Amèrica Precolombina, pp. 1120. Musée Barbier Mueller, Skira Editore, Barcelona.

PREM, H. J. y DYCKERHOFF, U.; 1986. El antiguo México. Historia y cultura de los pueblos mesoamericanos. Plaza \& Janes, Barcelona.

QUINTANA SAMAYOA, Ó.; 1999. El uso de los sitios arqueológicos y su incorporación a la vida contemporánea. En MUÑOZ COSME, G.; VIDAL LORENZO, C. y VALDÉS GÓMEZ, J. A. (coms.); Los Mayas. Ciudades Milenarias de Guatemala, pp. 77-82. Ministerio de Educación y Cultura de España, Ayuntamiento de Zaragoza, Generalitat Valenciana, IberCaja, talleres gráficos Edelvives, Zaragoza.

REX, A.; 2000. El rol del arte y los sistemas simbólicos en el proceso de evolución cultural. En BLANCO, R. (ed.); Arte Prehispánico: creación, desarrollo y presencia. Temas de la Academia, pp. 85-91. Academia Nacional de Bellas Artes, Mercantil S.A., Argentina, año 2, no 2.

SONDEREGUER, C.; 1998. Arquitectura precolombina. Catálogo de tipos de urbanismos, de obras y constructivos. 
Norte, Meso, Centro y Suramérica. Ediciones Corregidor, Buenos Aires.

STIERLIN, H.; 1997. L'Art de Mesoamèrica. En Arts Rituals del Nou Continent. Amèrica Precolombina, pp. 104-167. Musée Barbier Mueller, Skira Editore, Barcelona.

URIARTE, M. T.; 2012. Arte y arqueología en el altiplano central de México. Una visión a través del arte. Universidad Nacional Autónoma de México, Dirección General de Publicaciones y Fomento Editorial, Instituto de Investigaciones Estéticas, Siglo XXI Editores, México.

VIDAL, J. A. (ed.); 2002. El Mundo Precolombino. MMII Editorial Océano, Barcelona.

\section{Bibliografía específica}

AAVV; 2002. Espacios Sagrados. Arquitectura maya en la obra de Teoberto Maler. Universitat de València, Selvi Artes Gráficas, València.

BENITEZ, L.; 2009. Descendants of the Sun: Calendars, Myth and the Tiwanaku State. En YOUNG-SÁNCHEZ, M. (ed.); Tiwanaku: papers from the 2005 Mayer Center Symposium at the Denver Art Museum, pp. 49-82. Denver Art Museum, Denver.

BERENGUER RODRÍGUEZ, J.; 2000. Tiwanaku. Señores del Lago Sagrado. Museo Chileno de Arte Precolombino, Morgan Impresores, Santiago de Chile.

BISCHOF, H.; 2012. Die Kunst von Chavín - Ursprünge und Entwicklung. En FUX, P. (ed.); Chavín. Perus geheimnisvoller Anden-Tempel, pp. 134-157. Museum Rietberg Zürich un Verlag Scheidegger \& Spiess AG, Zürich.

BRUGHETTI, R.; 2000. Tiwanaku: etapas de su arte. En BLANCO, R. (ed.); Arte Prehispánico: creación, desarrollo y presencia. Temas de la Academia, pp. 7-14. Academia Nacional de Bellas Artes, Mercantil S.A., Argentina, año 2, no 2.

CARCELLER SINDREU, M.; 2010. El simbolismo de la montaña en la antigüedad. Estudio iconográfico de lo montañoso en las culturas de pensamiento mítico. Tesina codirigida por los Drs. Victòria Solanilla y Josep Cervelló, IEOPA-UAB, Barcelona.

CARLSON, U.; 2012a. Chavín enigmático. Simbolismo y su significación. Una contribución a la interpretación de la iconografía de Chavín. Iconografía Andina, Braunschweig, pp. 3-18.

CARLSON, U.; 2012b. Incorrect interpretations of the divine image of Chavín. Inaccurate interpretations of the divine image of Chavín. Andean Iconography, Braunschweig, pp. 19-30.

CARLSON, U.; 2013. The symbolism of reliefs and Wall paintings of ancient central and northern Peruvian coastal sites. A contribution to the understanding of the symbolism of ancient Peruvian art. Andean Iconography, Braunschweig, pp. 2-18.

CHINCHILLA MAZARIEGOS, 0.; 1999. La concepción del universo maya. El espacio y el tiempo. En MUÑOZ COSME, G.;
VIDAL LORENZO, C. y VALDÉS GÓMEZ, J. A. (coms.); Los Mayas. Ciudades Milenarias de Guatemala, pp. 37-42. Ministerio de Educación y Cultura de España, Ayuntamiento de Zaragoza, Generalitat Valenciana, IberCaja, talleres gráficos Edelvives, Zaragoza.

CLADOS, C.; 2009. New Perspective on Tiwanaku Iconography. En YOUNG-SÁNCHEZ, M. (ed.); Tiwanaku: papers from the 2005 Mayer Center Symposium at the Denver Art Museum, pp. 101-114. Denver Art Museum, Denver.

CONKLIN, W. J.; 2009. The Iconic Dimension in Tiwanaku Art. En YOUNG-SÁNCHEZ, M. (ed.); Tiwanaku: papers from the 2005 Mayer Center Symposium at the Denver Art Museum, pp. 115-132. Denver Art Museum, Denver.

DE LA GARZA, M.; 1998. Las fuerzas sagradas del Universo Maya. En PIÑA CHAN, R. y MATOS MOCTEZUMA, E.; Los mayas del período clásico, Corpus Precolombino. Sección Las Civilizaciones Mesoamericanas, pp. 101-140. Instituto Nacional de Antropología e Historia, Lunwerg Editores S.A., Barcelona.

DOMENICI, D.; 2007. Mayas: los tesoros de las antiguas civilizaciones. RBA Libros, S.A., Barcelona.

FUX, P.; 2012. Was ist Chavín? En FUX, P. (ed.); Chavín. Perus geheimnisvoller Anden-Tempel, pp. 21-24. Museum Rietberg Zürich un Verlag Scheidegger \& Spiess AG, Zürich.

GARCÍA CAPISTRÁN, H.; 2019. La montaña sagrada. Aspectos sobre la legitimación del poder en el Clásico Maya. Revista de Estudios de Cultura Maya, pp. 139-172. Centro de Estudios Mayas, Universidad Nacional Autónoma de México, vol. LIII, México.

GUSSINYER I ALFONSO, J.; 1992-93. Notas para el concepto de espacio en la arquitectura precolombina de Mesoamérica. Boletín Americanista, pp. 183-230, Universidad de Barcelona, Facultad de Geografía e Historia, Sección de Historia de América, año XXXIII, Barcelona.

GUTIÉRREZ USILLOS, A.; 2003. El dios de las tormentas y divinidades de la lluvia: iconografía del felino de los Andes Septentrionales. Anales del Museo de América,pp. 103118, Madrid.

HARRISON, Peter D.; 1999. The Lords of Tikal. Rulers of an ancient Maya city. Thames and Hudson, Nueva York.

HOOPES, J. W.; 2009. From Tiwanaku to Machu Picchu: Ushnus and the Architecture of Creation. En YOUNG-SÁNCHEZ, M. (ed.); Tiwanaku: papers from the 2005 Mayer Center Symposium at the Denver Art Museum, pp. 247-272. Denver Art Museum, Denver.

HOUSTON, S. D. (ed.); 1998. Function and Meaning in classic Maya architecture. Symposium at Dumbarton Oaks, 7th and 8th October 1994. Dumbarton Oaks Research Library and Collection, Washington D.C.

JANUSEK, J. W.; 1994. Tiwanaku: Civilization in the High Andes. Editions Routledge, Nueva York y Londres.

JANUSEK, J. W.; 2005. Patios hundidos, encuentros rituales y el auge de Tiwanaku como centro religioso panregional. Boletín de Arqueología PUCP, no 9, pp. 161-184. 
JANUSEK, J. W.; 2010. El surgimiento del urbanismo en Tiwanaku y del poder político en el altiplano andino. En MAKOWSKI HANULA, K. (comp.); Señores de los Imperios del Sol, pp. 1-19. Colección Arte y tesoros del Perú, Lima.

KOLATA, A.; 2004. The Flow of Cosmic Power: Religion, Ritual and The People of Tiwanaku. En LEVINSON, L. y MELUN, A. (eds.); Tiwanaku: ancestors of the Inca, pp. 96-125. Denver Art Museum, University of Nebraska Press, CS Graphics, Singapore.

LÓPEZ AUSTIN, A. y LÓPEZ LUJAN, L.; 2009. Monte SagradoTemplo Mayor. El cerro y la pirámide en la tradición religiosa mesoamericana. Instituto Nacional de Antropología e Historia y Universidad Nacional Autónoma de México, México.

LUMBRERAS, L. G.; 1993. Chavín de Huántar. Excavaciones en la Galería de las Ofrendas. VerlagPhilipp von Zabern, Mainz.

LUMBRERAS, L. G.; 2012. Religiöse Rite in Chavín un ihre überregionale Bedeutung. En FUX, P. (ed.); Chavín. Perus geheimnisvoller Anden-Tempel, pp. 184-196. Museum Rietberg Zürich un Verlag Scheidegger \& Spiess AG, Zürich.

MAKOWSKI HANULA, K.; 2009. Royal Statues, Staff Gods and the Religious Ideology of the Prehistoric State of Tiwanaku. En YOUNG-SÁNCHEZ, M. (ed.); Tiwanaku: papers from the 2005 Mayer Center Symposium at the Denver Art Museum, pp. 133-164. Denver Art Museum, Denver.

MAKOWSKI HANULA, K.; 2010. Vestido, arquitectura y mecanismo del poder en el Horizonte Medio. En MAKOWSKI HANULA, K. (comp.); Señores de los Imperios del Sol, pp. 1-17. Colección Arte y tesoros del Perú, Lima.

MANZANILLA, L.; 1992. Akapana. Una pirámide en el centro del mundo. Ed. Instituto Investigaciones Antropológicas, México.

MESÍA MONTENEGRO, C.; 2012. Die Entdeckung des Tempels und frühe Deutungsversuche. En FUX, P. (ed.); Chavín. Perus geheimnisvoller Anden-Tempel, pp. 126-133. Museum Rietberg Zürich un Verlag Scheidegger \& Spiess AG, Zürich.

MUÑOZ COSME, G.; 1999a. La arquitectura maya. En MUÑOZ COSME, G.; VIDAL LORENZO, C. y VALDÉS GÓMEZ, J. A. (coms.); Los Mayas. Ciudades Milenarias de Guatemala, pp. 43-50. Ministerio de Educación y Cultura de España, Ayuntamiento de Zaragoza, Generalitat Valenciana, IberCaja, talleres gráficos Edelvives, Zaragoza.

MUÑOZ COSME, G.; 1999b. Las ciudades y el medio natural. En MUÑOZ COSME, G.; VIDAL LORENZO, C. y VALDÉS GÓMEZ, J. A. (coms.); Los Mayas. Ciudades Milenarias de Guatemala, pp. 25-30. Ministerio de Educación y Cultura de España, Ayuntamiento de Zaragoza, Generalitat Valenciana, IberCaja, talleres gráficos Edelvives, Zaragoza.

OLMEDO VERA, B.; 1998. Los mayas del Clásico. En PIÑA CHAN, R. y MATOS MOCTEZUMA, E.; Los mayas del período clásico, Corpus Precolombino. Sección Las
Civilizaciones Mesoamericanas, pp. 9-100. Instituto Nacional de Antropología e Historia, Lunwerg Editores S.A., Barcelona.

PIÑA CHAN, R. y MATOS MOCTEZUMA, E.; 1998.Los mayas del período clásico, Corpus Precolombino. Sección Las Civilizaciones Mesoamericanas, pp. 141-225. Instituto Nacional de Antropología e Historia, Lunwerg Editores S.A., Barcelona.

RICK, J. W.; 2006. Un análisis de los centros ceremoniales del Periodo Formativo a partir de los estudios en Chavín de Huántar. Boletín de Arqueología PUCP, no 10, pp. 201-214.

RICK, J. W.; 2012a. Architektur und Kulträume in Chavín de Huántar. En FUX, P. (ed.); Chavín. Perus geheimnisvoller Anden-Tempel, pp. 158-173. Museum Rietberg Zürich un Verlag Scheidegger \& Spiess AG, Zürich.

RICK, J. W.; 2012b. Religion un Autorität in Chavín de Huántar. En FUX, P. (ed.); Chavín. Perus geheimnisvoller AndenTempel, pp. 174-183. Museum Rietberg Zürich un Verlag Scheidegger \& Spiess AG, Zürich.

RICK, J. W.; RODRIGUEZ, S.; MENDOZA, R. y KEMBEL, J. A.; 1998. La arquitectura del complejo ceremonial de Chavín de Huántar: Documentación tridimensional y sus implicancias. Boletín de Arqueología PUCP, no 2, pp. 181-214.

RIVERA DORADO, M.; 1999. Puertas al otro mundo. Religión y ritos de los mayas. En MUÑOZ COSME, G.; VIDAL LORENZO, C. y VALDÉS GÓMEZ, J. A. (coms.); Los Mayas. Ciudades Milenarias de Guatemala, pp. 51-56. Ministerio de Educación y Cultura de España, Ayuntamiento de Zaragoza, Generalitat Valenciana, IberCaja, talleres gráficos Edelvives, Zaragoza.

RUZ LHUILLIER, A.; 1992 (1972). El templo de las inscripciones de Palenque. Fondo de Cultura Económica, México, $2^{\text {a }}$ ed.

SONDEREGUER, C.; 1989. La pirámide templo en Mesoamérica. Morfoproporcionalidad. Arte al Día, Buenos Aires.

SONDEREGUER, C.; 2006. Pirámides y Templos de Egipto y América. Fundamentos ideológicos, morfoproporcionalidad, crítica estética. Nobuko, Buenos Aires.

ŠPRAJC, I.; 2001. Orientaciones astronómicas en la arquitectura prehispánica del centro de México. Instituto Nacional de Antropología e Historia, México.

STIERLIN, H.; 2001. Los mayas. Palacios y pirámides de la selva virgen. Taschen $\mathrm{GmbH}$, Italia.

TIESLER, V. y CUCINA, A. (eds.); 2004. Janaab'Pakal de Palenque. Vida y muerte de un gobernante maya. Universidad Nacional Autónoma de México y Universidad Autónoma de Yucatán, México.

VIDAL LORENZO, C.; 1996-97. Arquitectura maya: un nuevo enfoque para la clasificación estilística de los edificios del norte de Yucatán. "Ars Longa”, 7-8,pp. 15-31, Cuadernos de Arte, Departamento de Historia del Arte, Universitat de València, València.

VIDAL LORENZO, C.; 1999a. El descubrimiento de las Ciudades Milenarias de Guatemala. En MUÑOZ COSME, G.; 
VIDAL LORENZO, C. y VALDÉS GÓMEZ, J. A. (coms.); Los Mayas. Ciudades Milenarias de Guatemala, pp. 19-24. Ministerio de Educación y Cultura de España, Ayuntamiento de Zaragoza, Generalitat Valenciana, IberCaja, talleres gráficos Edelvives, Zaragoza.

VIDAL LORENZO, C.; 1999b. La expresión artística maya a través de los objetos ceremoniales. En MUÑOZ COSME, G.; VIDAL LORENZO, C. y VALDÉS GÓMEZ, J. A. (coms.); Los Mayas. Ciudades Milenarias de Guatemala, pp. 65-70. Ministerio de Educación y Cultura de España, Ayuntamiento de Zaragoza, Generalitat Valenciana, IberCaja, talleres gráficos Edelvives, Zaragoza.

VRANICH, A.; 2001. La pirámide de Akapana: reconsiderando el centro monumental de Tiwanaku. Boletín de Arqueología PUPC, número 5, pp. 295-308, Lima.

VRANICH, A.; 2009. The Development of the Ritual Core of Tiwanaku. En YOUNG-SÁNCHEZ, M. (ed.); Tiwanaku: papers from the 2005 Mayer Center Symposium at the Denver Art Museum, pp. 11-34. Denver Art Museum, Denver.

VRANICH, A.; 2010. Plataformas, plazas y palacios en Tiwanaku, Bolivia (500-1000). En MAKOWSKI HANULA, K. (comp.); Señores de los Imperios del Sol, pp. 1-11. Colección Arte y tesoros del Perú, Lima.

YOUNG-SÁNCHEZ, M.; 2004. The Art of Tiwanaku. En LEVINSON, L. y MELUN, A. (eds.); Tiwanaku: ancestors of the Inca, pp. 24-40. Denver Art Museum, University of Nebraska Press, CS Graphics, Singapore.

ZUIDEMA, R. T.; 2009. Tiwanaku Iconography and the Calendar. En YOUNG-SÁNCHEZ, M. (ed.); Tiwanaku: papers from the 2005 Mayer Center Symposium at the Denver Art Museum, pp. 83-100. Denver Art Museum, Denver.

\section{Apéndice 2: Material gráfico: anexo de imágenes}

\section{Lámina 1: Vistas aéreas actuales de Chavín de Huántar, Tiahuanaco, Tikal y Palenque.}

Chavín: http://www.mali.pe/chavin/ - última consulta: 30.09.2019

Tiahuanaco: https://www.andes-amazonia.com/dir_en/ tiahuanaco.html - última consulta 30.09.2019

Tikal: https://www.visitcentroamerica.com/visitar/parquenacional-ruinas-tikal/ - última consulta: 30.09.2019

Palenque: https://www.plataformaarquitectura.cl/ cl/898649/111-pueblos-magicos-en-mexico-que-tienesque-visitar/5b9bf1c9f197ccd53e000021-111-pueblosmagicos-en-mexico-que-tienes-que-visitar-imagen - última consulta: 30.09 .2019
Lámina 2: Mapas de los CeC de Chavín de Huántar, Tiahuanaco, Tikal y Palenque.

Chavín: Plano-mapa de Chavín de Huántar y trayectoria de los canales subterráneos de agua estudiados por John Rick y el Proyecto Arqueológico Chavín de Huántar - https:// nivardocordova.wordpress.com/tag/cultura-chavin/ - última consulta: 30.09 .2019

Tiahuanaco: Reconstrucción-mapa del centro ceremonial de Tiahuanaco - página 28 del artículo de Vranich, A.; 2009. The Development of the Ritual Core of Tiwanaku. En Young-Sánchez, M. (ed.); Tiwanaku: papers from the 2005 Mayer Center Symposium at the Denver Art Museum, pp. 11-34. Denver Art Museum, Denver.

Tikal: Mapa del centro ceremonial de Tikal, Petén - https:// www.gifex.com/detail/2011-11-24-15033/Mapa_de_ Tikal.html- última consulta: 30.09.2019

Palenque: Mapa de la zona arqueológica de Palenque, Chiapas - https://www.inah.gob.mx/zonas/163-zona-arqueologica-palenque - última consulta: 30.09.2019

\section{Lámina 3: Plano y reconstrucción del TA-V de Chavín de Huántar e iconografía del sitio.}

Plano y reconstrucción del TA-V de Chavín - https://historiaperuana.pe/periodo-autoctono/chavin-de-huantar/ - última consulta: 30.09.2019

Reconstrucción de la Galería del Lanzón - página 192 del artículo de Lumbreras, L. G.; 2012. Religiöse Rite in Chavín un ihre überregionale Bedeutung. En Fux, P. (ed.); Chavín. Perus geheimnisvoller Anden-Tempel, pp. 184-196. Museum Rietberg Zürich un Verlag Scheidegger \& Spiess AG, Zürich.

Obelisco Tello: dibujo y reconstrucción pictórica - página 190-191 del artículo de Lumbreras, L. G.; 2012. Religiöse Rite in Chavín un ihre überregionale Bedeutung. En Fux, P. (ed.); Chavín. Perus geheimnisvoller Anden-Tempel, pp. 184-196. Museum Rietberg Zürich un Verlag Scheidegger \& Spiess AG, Zürich.

Relieves y reconstrucción de la Plaza circular hundida de Chavín - página 189 del artículo de Lumbreras, L. G.; 2012. Religiöse Rite in Chavín un ihre überregionale Bedeutung. En Fux, P. (ed.); Chavín. Perus geheimnisvoller AndenTempel, pp. 184-196. Museum Rietberg Zürich un Verlag Scheidegger \& Spiess AG, Zürich. 
Lámina 4: Reconstrucción de CeC de Tiahuanaco e iconografía del sitio.

Reconstrucción del centro ceremonial del sitio de Tiahuanaco - https://i.pinimg.com/originals/5b/d5/5e/5bd55 ede63da4dc0a2b83fe850169102.jpg - última consulta: 30.09.2019

Vista del Templo de Kalasasaya y el Templo Semisubterráneo de Tiahuanaco - página 31 del artículo de Benítez, L.; 2009. Descendants of the Sun: Calendars, Myth and the Tiwanaku State. En Young-Sánchez, M. (ed.); Tiwanaku: papers from the 2005 Mayer Center Symposium at the Denver Art Museum, pp. 49-82. Denver Art Museum, Denver.

Puerta del sol de Tiahuanaco - página 66 del artículo de Benítez, L.; 2009. Descendants of the Sun: Calendars, Myth and the Tiwanaku State. En Young-Sánchez, M. (ed.); Tiwanaku: papers from the 2005 Mayer Center Symposium at the Denver Art Museum, pp. 49-82. Denver Art Museum, Denver.

Monolito Ponce - https://lascronicasdeasier2.wordpress. com/2018/10/15/las-ruinas-del-altiplano/- última consulta: 30.09 .2019

Monolito Bennett - página 139 del artículo de Makowski Hanula, K.; 2009. Royal Statues, Staff Gods and the Religious Ideology of the Prehistoric State of Tiwanaku. En Young-Sánchez, M. (ed.); Tiwanaku: papers from the 2005 Mayer Center Symposium at the Denver Art Museum, pp. 133-164. Denver Art Museum, Denver.

Monolito El fraile - https://es.wikipedia.org/wiki/Monolito_Fraile - última consulta: 30.09.2019

\section{Lámina 5: Vista actual y reconstrucción del CeC de Tikal; alzado T1 y $T 2$.}

Vista actual del centro ceremonial de Tikal - https://miviaje. com/ver-parque-nacional-de-tikal-guatemala/ - última consulta: 30.09.2019

Reconstrucción del centro ceremonial de Tikal - vista panorámica de la ciudad - https://arquitecturaguatemalteca1url.blogspot.com/search?q=tikal - última consulta: 30.09.2019

Alzado Templo 1 de Tikal - Sondereguer, C.; 1989: 36. La pirámide templo en Mesoamérica. Morfoproporcionalidad. Arte al Día, Buenos Aires.

Alzado Templo 2 de Tikal - Sondereguer, C.; 1989: 37. La pirámide templo en Mesoamérica. Morfoproporcionalidad. Arte al Día, Buenos Aires.

\section{Lámina 6: Reconstrucción del CeC de Palenque; vista actual y alzado del Templo de las Inscripciones y vista del Complejo de las Cruces.}

Reconstrucción del centro ceremonial de Palenque - http:// sanchezanguloarquitectos.blogspot.com/2010/10/ palenque-chiapas-mexico_28.html - última consulta: 30.09.2019

Vista actual del templo de las Inscripciones de Palenque - https://www.inah.gob.mx/boletines/5432-descubrensistema-de-canales-bajo-el-templo-de-las-inscripcionesde-palenque - última consulta: 30.09.2019

Alzado del templo de las Inscripciones de Palenque - Stierlin, H.; 2001: 75. Los mayas. Palacios y pirámides de la selva virgen. Taschen $\mathrm{GmbH}$, Italia.

Conjunto de las Cruces: http://unvisitantenuevo.blogspot. com/2016/07/palenque-la-ciudad-del-rey-pakal.html última consulta 30.09.2019

\section{Lámina 7: Reconstrucciones de los CeC de Chavín de Huán- tar, Tiahuanaco, Tikal y Palenque.}

Chavín: Reconstrucción isométrica del centro ceremonial de Chavín - página 163 del artículo de RICK, J. W.; 2012a. Architektur und Kulträume in Chavín de Huántar. En FUX, P. (ed.); Chavín. Perus geheimnisvoller Anden-Tempel, pp. 158-173. Museum Rietberg Zürich un Verlag Scheidegger \& Spiess AG, Zürich.

Tiahuanaco: Reconstrucción del centro ceremonial del sitio de Tiahuanaco - https://i.pinimg.com/originals/5b/d5/ 5e/5bd55ede63da4dc0a2b83fe850169102.jpg - última consulta: 30.09.2019

Tikal: Reconstrucción del centro ceremonial de Tikal. La ciudad roja - http://glendacubias.blogspot.com/2012/11/ porque-tikal-era-una-ciudad-roja.html - última consulta: 30.09.2019

Palenque: Reconstrucción del complejo ceremonial de Palenque - https://twitter.com/zamna2012/status/502581128084357120 - última consulta: 30.09.19 